\title{
Development of a Monte Carlo simulation model to predict pasteurized fluid milk spoilage due to post-pasteurization contamination with gram-negative bacteria
}

\author{
S. Lau, ${ }^{1} \oplus$ A. Trmcic, ${ }^{1} \odot$ N. H. Martin, ${ }^{1} \odot$ M. Wiedmann, ${ }^{1} \oplus$ and S. I. Murphy ${ }^{2 *} \oplus$ \\ ${ }^{1}$ Milk Quality Improvement Program, Department of Food Science, Cornell University, Ithaca, NY 14853 \\ ${ }^{2}$ Department of Population Medicine and Diagnostic Sciences, Cornell University, Ithaca, NY 14853
}

\begin{abstract}
Psychrotolerant gram-negative bacteria introduced as post-pasteurization contamination (PPC) are a major cause of spoilage and reduced shelf life of hightemperature, short-time pasteurized fluid milk. To provide improved tools to (1) predict pasteurized fluid milk shelf life as influenced by PPC and (2) assess the effectiveness of different potential interventions that could reduce spoilage due to $\mathrm{PPC}$, we developed a Monte Carlo simulation model that predicts fluid milk spoilage due to psychrotolerant gram-negative bacteria introduced as PPC. As a first step, 17 gram-negative bacterial isolates frequently associated with fluid milk spoilage were selected and used to generate growth data in skim milk broth at $6^{\circ} \mathrm{C}$. The resulting growth parameters, frequency of isolation for the 17 different isolates, and initial concentration of bacteria in milk with PPC, were used to develop a Monte Carlo model to predict bacterial number at different days of shelf life based on storage temperature of milk. This model was then validated with data from d 7 and 10 of shelf life, collected from commercial operations. The validated model predicted that the parameters (1) maximum growth rate and (2) storage temperature had the greatest influence on the percentage of containers exceeding 20,000 cfu/mL standard plate count on d 7 and 10 (i.e., spoiling due to PPC), which indicates that accurate data on maximum growth rate and storage temperature are important for accurate predictions. In addition to allowing for prediction of fluid milk shelf life, the model allows for simulation of "what-if" scenarios, which allowed us to predict the effectiveness of different interventions to reduce overall fluid milk spoilage due to PPC through a set of proof-of-concept scenario (e.g., frequency of PPC in containers reduced from $100 \%$ to $10 \%$; limiting distribution temperature to a maximum
\end{abstract}

Received September 20, 2021.

Accepted November 10, 2021

*Corresponding author: sim39@cornell.edu of $6^{\circ} \mathrm{C}$ ). Combined with other models, such as previous models on fluid milk spoilage due to psychrotolerant spore-forming bacteria, the data and tools developed here will allow for rational, digitally enabled, fluid milk shelf life prediction and quality enhancement.

Key words: fluid milk, spoilage, post-pasteurization contamination, Monte Carlo simulation

\section{INTRODUCTION}

Microbial spoilage is a contributor to food loss and waste globally, and represents a challenge for maintaining the quality and expected shelf life of many foods, including fluid milk (Hoover, 2017; FAO, 2019). In the United States, dairy products are among the top 3 food groups representing the largest share of the total volume of food lost or wasted, with fluid milk responsible for approximately $65 \%$ of food wasted in volume attributed to dairy products (Buzby et al., 2014). The value of fluid milk loss in the US is estimated to be $\$ 6.4$ billion per year (Buzby et al., 2014). Globally, fluid milk production, processing, and transport is estimated to be responsible for $2.4 \mathrm{~kg}$ of $\mathrm{CO}_{2}$ equivalents $\left(\mathbf{C O}_{2} \mathbf{e}\right)$ per kilogram of milk (FAO, 2010). Thus, reducing the volume of fluid milk wasted represents an opportunity with potential for economic and environmental impact.

Although the quality of fluid milk and dairy products can be degraded via different mechanisms (e.g., chemical, microbial), microbial growth is the predominant mechanism for pasteurized fluid milk spoilage (Martin et al., 2016). One of the main causes of microbial fluid milk spoilage is post-pasteurization contamination (PPC) with gram-negative bacteria during processing. Existing data show that in the United States approximately $50 \%$ of HTST-pasteurized fluid milk spoilage is due to PPC (Alles et al., 2018; Reichler et al., 2018). Although PPC can introduce a variety of different organisms, key organisms of concern for their potential to cause spoilage are those that can grow in refrigerated fluid milk (e.g., around $6^{\circ} \mathrm{C}$ ). Most studies suggest that the majority of fluid milk spoilage is caused by psychro- 
tolerant non-coliform gram-negative bacteria from the genus Pseudomonas (Ranieri and Boor, 2009; Martin et al., 2018; Reichler et al., 2018). When these organisms are introduced to fluid milk as a result of PPC, they usually grow to $>20,000 \mathrm{cfu} / \mathrm{mL}$ over $10 \mathrm{~d}$, resulting in shelf life that is typically at least 5 to $7 \mathrm{~d}$ shorter, compared with fluid milk that is only contaminated by psychrotolerant gram-positive spore-formers (Ranieri and Boor, 2009). Identification of strategies to reduce PPC has potential to reduce the overall amount of fluid milk spoilage and extend shelf life, which would hence reduce fluid milk waste.

Both identification of PPC and implementation of PPC control strategies can be challenging. Key challenges with identification of PPC include, but are not limited to the following: (1) PPC can often occur at low levels (e.g., $<10 \mathrm{cfu}$ per container), requiring tedious microbiological methods for identification; (2) the nature of contamination is frequently sporadic; and (3) a large number of possible root causes for PPC exist, ranging from improperly designed or implemented cleaning and sanitation approaches to procedures that facilitate cross-contamination (Sunga et al., 1970; Schröder, 1984; Gruetzmacher and Bradley, 1999; Reichler et al., 2018). Interventions to reduce PPC in a plant can include enhancing good manufacturing practices and cleaning sanitation procedures, improving preventative maintenance, as well as improving sanitary equipment and plant design (Reichler et al., 2020; Murphy et al., 2021). Another hurdle to reducing PPC is the difficulty of assessing the expected effects of interventions on fluid milk shelf life, thus hampering the ability of companies to assess the potential return on investment that could be achieved with different interventions.

One solution to support improved decision-making regarding selection and implementation of PPC interventions is to use modeling approaches. To that end, we report the development and validation of a Monte Carlo simulation model of pasteurized fluid milk spoilage due to PPC to estimate the concentration of gram-negative bacteria throughout shelf life and predict the effects of different intervention strategies.

\section{MATERIALS AND METHODS}

\section{Identification and Selection of Bacterial Representatives of PPC}

Data reported in a previous comprehensive study of pasteurized fluid milk spoilage in 10 processing plants across the northeastern United States (Reichler et al., 2018) were used to select representative bacterial genera, species, and strains that are commonly associated with fluid milk spoilage due to PPC, for determina- tion of growth parameters needed for the development of the fluid milk model reported here. In the Reichler et al. (2018) study, a total of 459 gram-negative isolates obtained from fluid milk samples with PPC were characterized by $16 \mathrm{~S}$ rDNA sequencing and assigned a sequence type (ST) based on an approximately 552-nucleotide region (Reichler et al., 2018). Data from $16 \mathrm{~S} \mathrm{rDNA}$ were also used to assign isolates to genus and species. In this study, using the Reichler et al. (2018) data set, Pseudomonas groups were then assigned to 1 of 8 phylogenomic groups based on the species (i.e., groups of related Pseudomonas species, such as the Pseudomonas fluorescens group), adapted from the group assignment method used by Garrido-Sanz et al. (2016). Specifically, isolates from the Reichler et al. (2018) data set were assigned to the previously defined groups from the Garrido-Sanz et al. (2016) study based on species; we then divided the largest group ( $P$. fluorescens group) into clades. Data on the frequency of different ST among the characterized 459 isolates of gram-negative bacteria (Table 1) were used to select 17 isolates for growth experiments.

Analysis of the Reichler et al. (2018) data set revealed that the majority of isolates linked to PPC were identified as Pseudomonas spp. (324 out of 459 isolates). Fifteen Pseudomonas ST were isolated $\geq 5$ times and represented the most frequent Pseudomonas ST identified in this study. These $15 \mathrm{ST}$ represented 5 of the 9 proposed Pseudomonas groups (e.g., P. fluorescens group, Pseudomonas fragi group), but also included 1 ST (ST 24) that could not be unambiguously classified to species and may represent 1 of 2 Pseudomonas groups (Pseudomonas mandelii or Pseudomonas corrugata). The ST classified into the $P$. fluorescens group represented 7/15 Pseudomonas ST isolated $\geq 5$ times and 4 of the 6 major $16 \mathrm{~S}$ clades within the $P$. fluorescens group. To provide representation of the Pseudomonas most commonly associated with PPC, we selected (1) the ST most commonly isolated in each of the $4 P$. fluorescens clades (e.g., P. fluorescens clade 5; Table 1) as well as (2) the ST found most frequently among each of the 4 other Pseudomonas groups that were represented among this data set; the specific isolate representing each ST was randomly selected (using a random number generator) for inclusion in the growth experiments. Although this process yielded 8 different Pseudomonas isolates (4 from the P. fluorescens group and 4 from other Pseudomonas groups, including P. fragi, Pseudomonas chloraphis, Pseudomonas putida, and P. mandelii) that were used for growth curve experiments, a $P$. chloraphis isolate initially selected was removed from the final data set due to a contamination event.

In addition to Pseudomonas, the isolates reported by Reichler et al. (2018) as linked to PPC also included 


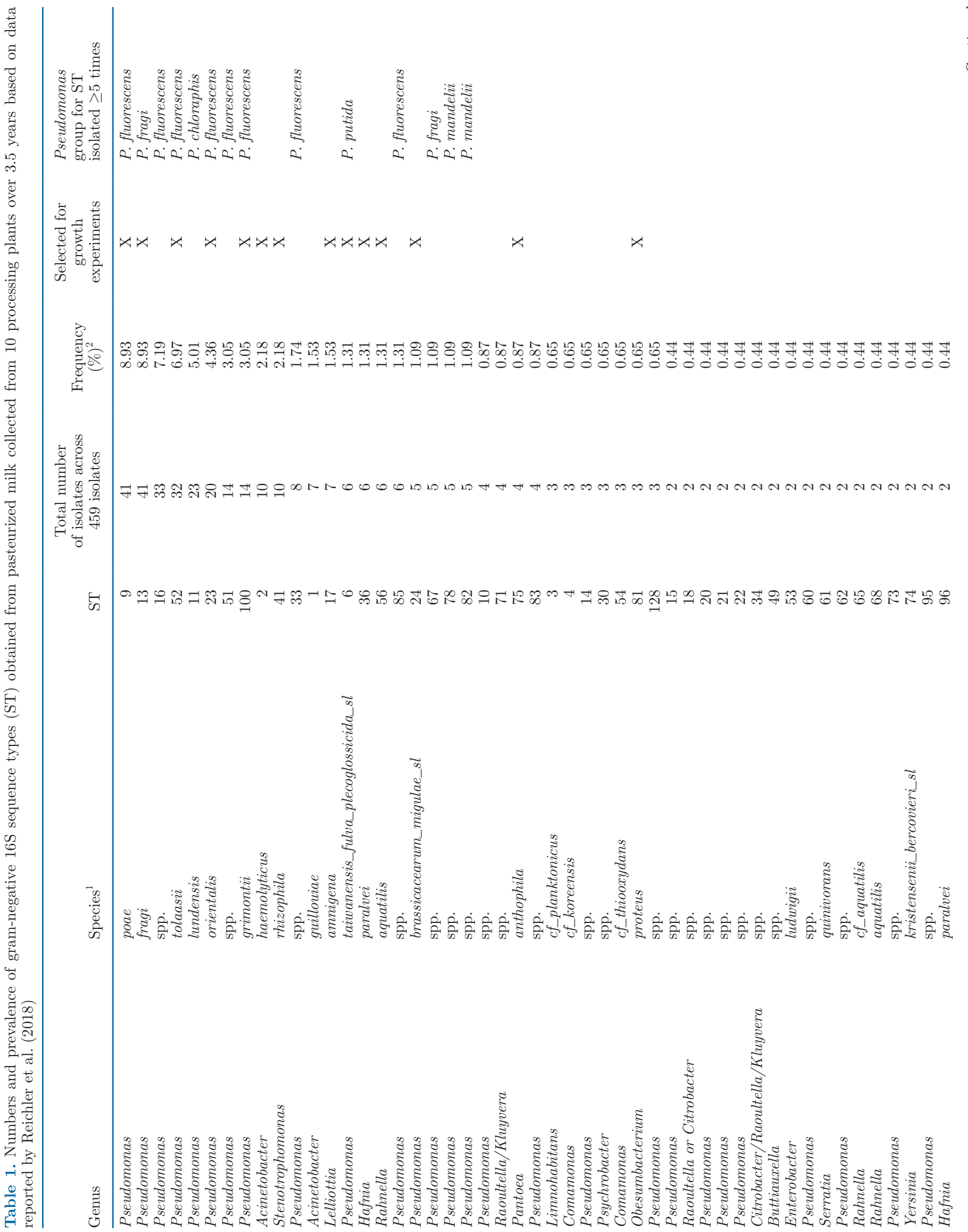




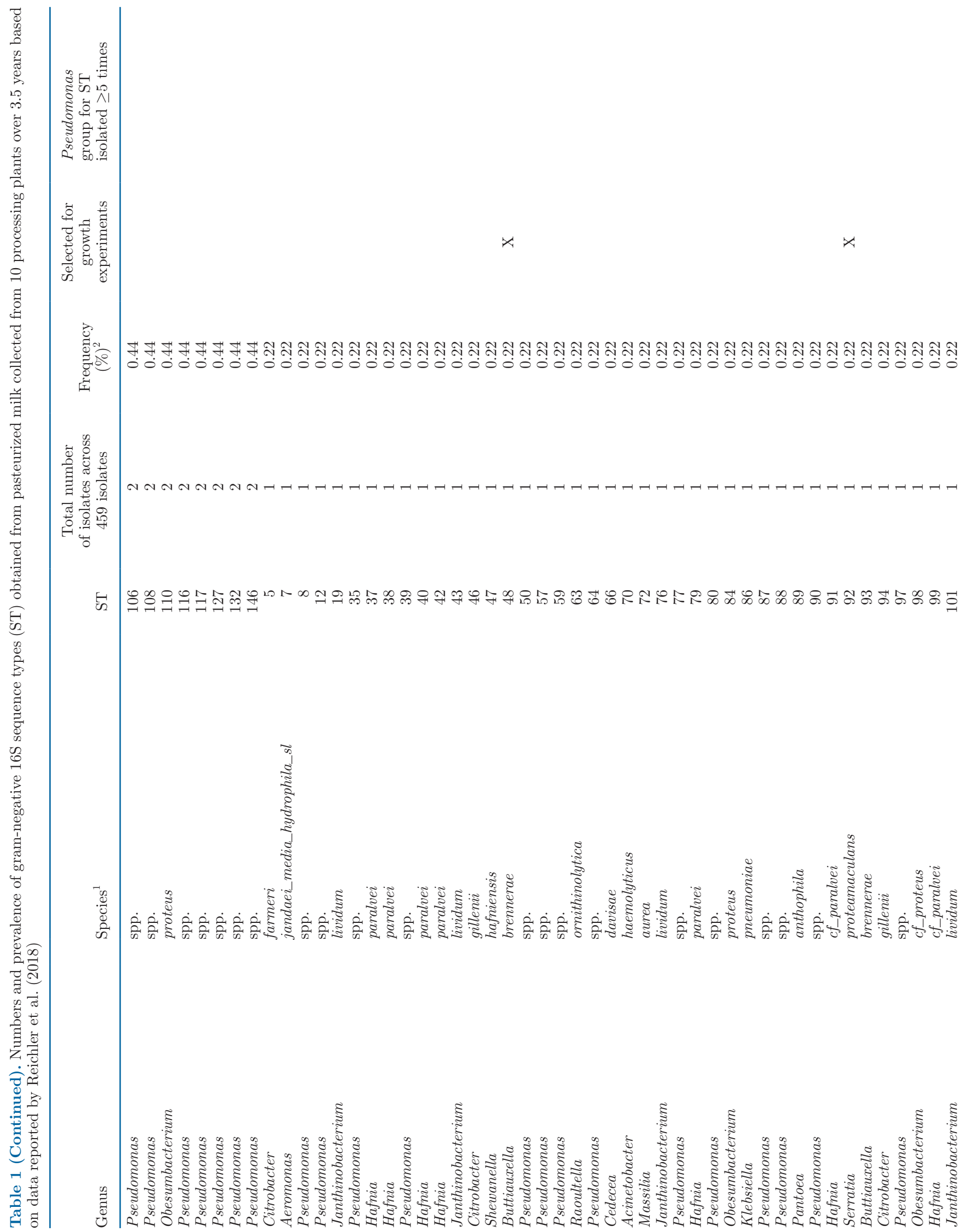


Lau et al.: PREDICTIVE MODEL OF POST-PASTEURIZATION CONTAMINATION




the genera Buttiauxella, Hafnia, Lelliottia, Obesumbacterium, Pantoea, Rahnella, Serratia, Janthinobacterium, Acinetobacter, Comamonas, and Stenotrophomonas. For 10 of these 11 genera of gram-negative bacteria, 1 isolate representing the most common ST was randomly selected for inclusion in the growth experiments (a Comamonas isolate was not included, due to a laboratory error); if multiple ST included the same number of isolates (e.g., each of the 5 Janthinobacterium isolates represented a different ST), 1 ST was randomly selected. Janthinobacterium spp. isolate FSL R10-0933 (ST 76), which was initially selected, did not grow in brain heart infusion (BHI) broth incubated at $32^{\circ} \mathrm{C}$ and was replaced with another Janthinobacterium spp. isolate, FSL R10-1587 (ST 102). Overall, this approach yielded 17 isolates (7 Pseudomonas, 7 Enterobacteriaceae, and 3 other genera of non-Enterobacteriaceae gram-negative bacteria) that were used for growth experiments (Table 2 ). The FSL numbers of strains refer to the Food Science Laboratory at Cornell University. Additional isolate information can be found via the Food Microbe Tracker Database (www.foodmicrobetracker.com; Vangay et al., 2013).

\section{Determination of Cold-Growth Characteristics at $6^{\circ} \mathrm{C}$}

To determine cold-growth characteristics in skim milk broth (SMB; Becton, Dickinson and Co.), all selected isolates were streaked from frozen culture stocks onto BHI agar (Becton, Dickinson and Co.). Following 24-h incubation at $32^{\circ} \mathrm{C}$, a single colony was selected from the BHI plate and used to inoculate 5 $\mathrm{mL}$ of BHI broth, which was subsequently incubated overnight (approximately $12-18 \mathrm{~h}$ ) at $32^{\circ} \mathrm{C}$. Bacterial numbers in the overnight $\mathrm{BHI}$ cultures were enumerated by plating appropriate dilutions on BHI plates, which were subsequently incubated at $32^{\circ} \mathrm{C}$ for $24 \mathrm{~h}$; the undiluted overnight cultures were stored during these $24 \mathrm{~h}$ at $4^{\circ} \mathrm{C}$ before being used for inoculation of SMB. The enumeration results were used to determine the volume and dilution necessary to inoculate SMB at a starting concentration of approximately $10^{3} \mathrm{cfu} /$ $\mathrm{mL}$. The inoculated SMB was incubated at $6^{\circ} \mathrm{C}$, and bacterial numbers were enumerated (with 2 technical replicates) every $4 \mathrm{~h}$ during the first $12 \mathrm{~h}$ to capture the lag phase, every $12 \mathrm{~h}$ during the next $60 \mathrm{~h}$, and every 24 $\mathrm{h}$ until 2 time points were taken during the stationary phase so that we could fully capture the exponential phase. The cold-growth characteristics for each isolate were determined based on at least 3 separate biological replicates of the experiment. Isolate cold-growth data were managed in Excel (version 2108, Microsoft Corp.) and were joined and cleaned in $\mathrm{R}$ version 3.6.2 (R Core Team, 2019).

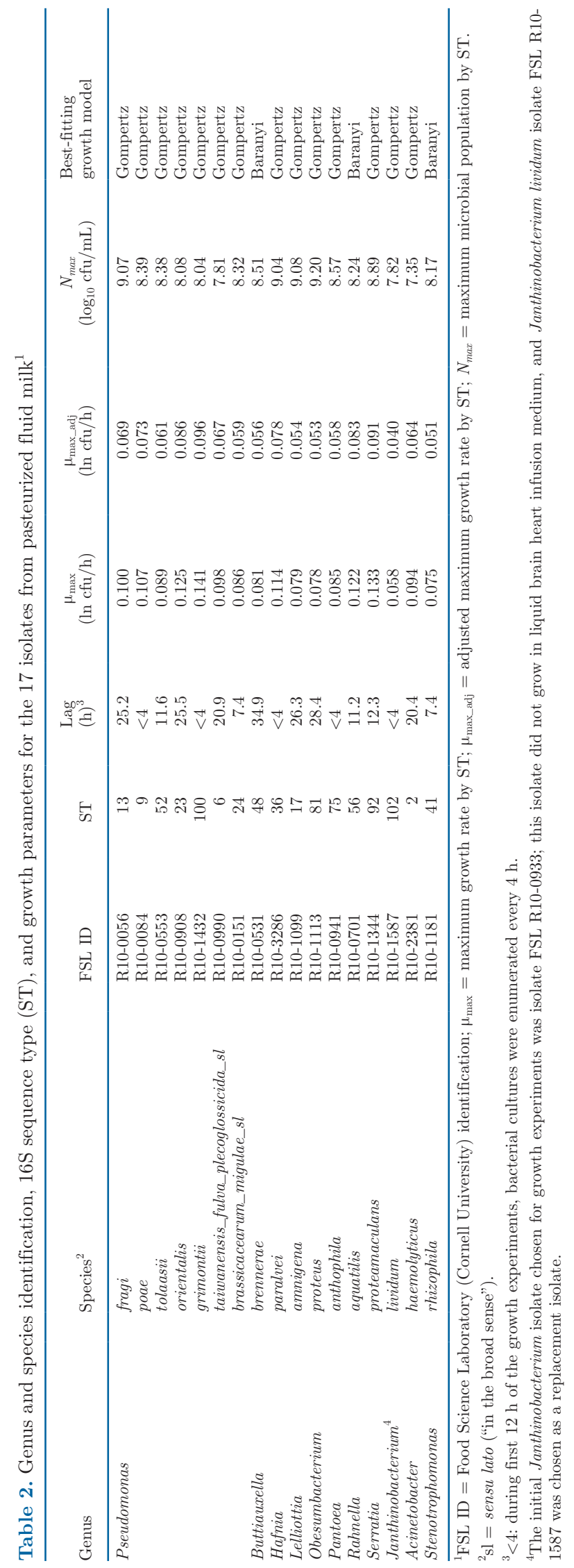

Journal of Dairy Science Vol. 105 No. 3, 2022 


\section{Determining Cold-Growth Parameters}

The nlsMicrobio package version 0.0-1 (Baty and Delignette-Muller, 2017) in $\mathrm{R}$ version 3.6.2 ( $\mathrm{R}$ Core Team, 2019) was used to fit the data for the 3 biological replicates to the Buchanan (Buchanan et al., 1997), Baranyi (Baranyi and Roberts, 1994), and Gompertz (Zwietering et al., 1991) growth models (Table 2). The Bayesian information criterion values calculated with the AICcmodavg package version 2.3-1 (Mazerolle 2020) in $\mathrm{R}$ version 3.6.2 were used to select the growth model with the best fit. Initially, for each ST, the bacterial enumeration data for each time point were averaged across biological replicates. The averaged data were plotted to estimate the starting values of the growth parameters; these starting value estimates allowed for convergence to be achieved and allowed us to use the iterative estimation procedure in the nlsMicrobio package version 0.0-1 to best fit the data (Baty et al., 2015). The averaged data were then fitted with the growth models; this approach allowed us to identify a single growth model that best fit the data; the best-fit model was selected based on Bayesian information criterion values. Fitting the averaged values also allowed for identification of outliers, using all the growth data over time. To identify potential outliers of the bacterial enumeration data, residuals of individual data points with respect to the best-fit model were retrieved; data points were considered outliers if their residuals were identified as outliers among all residuals, based on the interquartile range method (Vinutha et al., 2018). After removal of the outliers, the remaining bacterial enumeration data were fitted with the best-fit growth model again, and the growth parameters were determined for the respective ST, including (1) lag phase (h), (2) maximum growth rate $\left(\boldsymbol{\mu}_{\max }, \ln \mathrm{cfu} / \mathrm{h}\right)$, and (3) maximum cell density $\left(\log _{10} \mathrm{cfu} / \mathrm{mL}\right.$; Table 2$)$.

\section{Predictive Model Development}

Model Assumptions. For the model developed here, PPC organisms were assumed to be the only cause of spoilage in each simulated half-gallon of milk $(1,900 \mathrm{~mL})$. Furthermore, each simulated half-gallon of milk was assigned an initial concentration, storage temperature, and ST. Each half-gallon container of milk was assumed to be stored at a constant temperature during shelf life. The baseline model comprises 10,000 iterations, and each iteration is considered to represent one lot. Here, a lot is defined as 10 fluid milk containers coming from the same processing facility and the same processing day, modeled across $14 \mathrm{~d}$ of shelf life; as a result, a total of 100,000 containers are simulated. For the baseline model, it was assumed that the frequency of PPC for the 10 half-gallon containers in all simulated lots was $100 \%$ (i.e., all simulated containers had PPC); however, if the assigned initial concentration was less than 1 cfu per half-gallon, it was assumed that PPC did not occur in that container.

The effects of lower frequencies of PPC using this model can be assessed by assuming that the half-gallon containers modeled here represent only a certain portion of a given lot; for example, if the processing plant expects that only $50 \%$ of a lot are to be affected by PPC, then the model developed here would represent $50 \%$ of the processing plant's lot. The other $50 \%$ of the lot would be expected to spoil due to psychrotolerant spore-forming bacteria, and spoilage patterns could be assessed with a previously published "spore-former model" (Buehler et al., 2018), or, in the case of fewer than 1 psychrotolerant spore per container, not spoil during the storage period.

When conducting our analysis, we used 20,000 cfu/ $\mathrm{mL}$ SPC as the microbial threshold for defining spoilage in this study. This value is the upper limit of the concentration a container can reach before it is deemed unacceptable from a quality standpoint, or what we refer to as spoiled fluid milk. We appreciate that this is a conservative threshold (which ensures compliance with the US Pasteurized Milk Ordinance limits for pasteurized milk; FDA, 2019); an alternative threshold can be easily used by this model if so desired.

Model Parameters. Six parameters were included in the model developed here (Table 3), including (1) storage temperature $(\mathbf{T}),(2)$ initial concentration of gram-negative bacteria in pasteurized milk $\left(\boldsymbol{N}_{\mathbf{0}}\right)$, (3) frequency of different 16S rDNA ST of gram-negative bacteria as PPC $\left(\mathbf{F}_{\mathbf{S T}}\right)$, (4) adjusted maximum growth rate by $\mathrm{ST}\left(\boldsymbol{\mu}_{\text {max_adj }}\right),(5)$ lag phase by $\mathrm{ST}\left(\boldsymbol{t}_{\text {lag }}\right)$, and (6) maximum microbial population by ST $\left(\boldsymbol{N}_{\max }\right)$.

For parameter (1), storage temperature $(\mathrm{T})$, a temperature distribution following a modified Laplace distribution was used (Table 3), based on a previous study that analyzed home refrigeration temperatures from a 2005 national survey in the US collected by Research Triangle Institute International (Pouillot et al., 2010). The minimum and maximum temperatures that could be drawn from the distribution were set at $-1^{\circ} \mathrm{C}$ and $15^{\circ} \mathrm{C}$, respectively, to prevent unrealistically low or high storage temperatures.

No primary data were available to estimate parameter (2), the initial concentration of gram-negative bacteria $\left(N_{0}\right)$. Values for this parameter were thus derived from total gram-negative count data obtained during shelf life of commercially produced HTST milk collected by Cornell University's Milk Quality Improvement Program Voluntary Shelf Life (VSL) Program between January 2015 and June 2018 (N. Martin, unpublished 
data). Briefly, total gram-negative counts were determined by plating on crystal violet tetrazolium agar (CVTA), followed by incubation at $21^{\circ} \mathrm{C}$ for $48 \mathrm{~h}$, and then enumeration. The VSL program has been previously described (Martin et al., 2012; Murphy et al., 2021). The criteria for microbial count data used as $N_{0}$ represent only samples that were shown to spoil due to gram-negative bacteria; samples had to have enumeration of gram-negative organisms on CVTA plates. Samples that were below the detection limit, samples that had only 1 data point across shelf life, and samples that showed low levels of bacterial growth on CVTA $(<1,000 \mathrm{cfu} / \mathrm{mL})$ were not included. Of the remaining samples, we excluded those that showed low levels of bacterial growth on SPC $(<20,000 \mathrm{cfu} / \mathrm{mL})$, which would be indicative of spoilage due to spore-formers, including Paenibacillus, which may show growth on CVTA (N. Martin, unpublished data). Microbial count data during shelf life of the 83 samples deemed to have spoiled due to growth by gram-negative bacteria were used to estimate $N_{0}$, assuming linear growth over shelf life; a least squares regression was used to determine initial microbial concentration at $\mathrm{d} 1$, which is one day after processing. With this approach, we determined a log normal distribution for this input parameter (mean $=0.38 \log _{10} \mathrm{cfu} / \mathrm{mL}, \mathrm{SD}=1.11 \log _{10} \mathrm{cfu} / \mathrm{mL}$; Figure 1$)$. The maximum initial concentration for each simulated half-gallon was set at $3 \log _{10} \mathrm{cfu} / \mathrm{mL}$ to avoid simulations with unrealistically high $N_{0}$.

Parameter (3), the frequency of spoilage due to different $\mathrm{ST}\left(\mathrm{F}_{\mathrm{ST}}\right)$, represents the expected frequency (percentage of half-gallon containers) with which different ST occur as PPC. The frequency of an individual ST in this study was assumed to be the frequency with which that ST was isolated from fluid milk samples; for example, ST 15, which represented $0.436 \%$ of isolates characterized by Reichler et al. (2018), was assumed to be responsible for PPC of $0.436 \%$ of modeled halfgallon containers.

Growth characteristics [i.e., $\mu_{\text {max } \_ \text {adj }}, t_{\text {lag }}$, and $N_{\max }$; parameters (4), (5), and (6)] for the 17 different ST were obtained from the experimental data and subsequent growth modeling detailed earlier; values of each parameter for a given ST are shown in Table 2. Ratkowsky's square root model $\left[\sqrt{r}=b\left(T-T_{0}\right)\right]$ with a $T_{0}$ value of $-4.15^{\circ} \mathrm{C}$ was used to adjust $t_{\text {lag }}$ and $\mu_{\max }$ for different temperatures (Ratkowsky et al., 1982). This approach yielded growth parameters for 17 of $124 \mathrm{ST}$ that could cause PPC in the model developed here. Growth parameters were assigned to the other 107 ST using an approach similar to that previously reported by Buehler et al. (2018). Briefly, $16 \mathrm{~S}$ rDNA sequence data for each of the ST without experimentally ob- tained growth parameters $\left(\mathbf{S T}_{\text {no exp growth }}\right)$ were used to determine the most closely related ST with experimental growth data $\left(\mathbf{S T}_{\exp \text { growth }}\right)$. For this, Basic Local Alignment Search (BLAST) was used to first determine the $\mathrm{ST}_{\text {exp growth }}$ that showed the highest percentage of nucleotide similarity to each $\mathrm{ST}_{\text {no exp growth }}$; a partial $16 \mathrm{~S}$ rDNA maximum-likelihood phylogenetic tree of all 124 ST (Supplemental Figure S1, https://doi.org/10.7298/ yth9-zq08; Lau et al., 2021), built based on data from Reichler et al. (2018), was used to confirm assignment of the most closely related $\mathrm{ST}_{\text {exp growth }}$ in a situation where $\mathrm{ST}_{\text {no exp growth }}$ shows equal percent similarity to 2

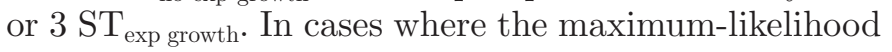
tree would not allow for identification of the most

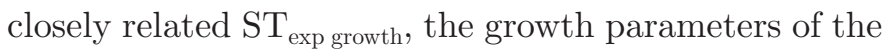
$\mathrm{ST}_{\text {exp growth }}$ most closely related to an $\mathrm{ST}_{\text {no exp growth }}$ were averaged, and the growth model with the lowest Bayesian information criterion value was selected as the bestfitting model.

Model Simulations. The simulation model was programmed in $\mathrm{R}$ version 3.6.2 ( $\mathrm{R}$ Core Team, 2019), predicting the concentration of PPC organisms in milk containers across $14 \mathrm{~d}$ of shelf life. The model was simulated for 10,000 iterations, with 10 half-gallon containers simulated per each iteration. Conceptually, this represents 10,000 unique lots and 10 half-gallon containers of milk per lot, for a total of 100,000 simulated half-gallon containers of milk. Raw data and the $\mathrm{R}$ code can be found on GitHub: https://github.com/FSL-MQIP/MC -2020/tree/master/Sam_FFAR_PPCmodel.

Model Validation. The model was validated with d 7 and d 10 shelf life data for milk collected by Cornell's VSL program from commercial operations between July 2018 and May 2019 (N. Martin, unpublished data); this allowed us to validate the model with data independent from those used to estimate input parameter $N_{0}$ (i.e., initial concentration of gram-negative bacteria). A total of 127 samples from this data set were used to validate the model for $\mathrm{d} 7$, and a total of 145 samples from this data set were used to validate the model for $\mathrm{d} 10$. These samples were identified as having spoiled due to growth by gram-negative bacteria (using the same criteria used to identify samples for estimation of $N_{0}$ ) and were thus deemed to represent PPC spoilage. For validation, the model was set to use a constant storage temperature of $6^{\circ} \mathrm{C}$ (rather than the modified Laplace distribution in Table 3) to reflect the storage conditions of the VSL samples used for validation. The Kolmogorov-Smirnov test, implemented using the dgof package version 1.2 (Arnold and Emerson, 2013), was used to compare the distribution of simulated counts and observed counts for $7 \mathrm{~d}$ and $10 \mathrm{~d}$ in $\mathrm{R}$ version 3.6.2 ( $\mathrm{R}$ Core Team, 2019). 
Lau et al.: PREDICTIVE MODEL OF POST-PASTEURIZATION CONTAMINATION

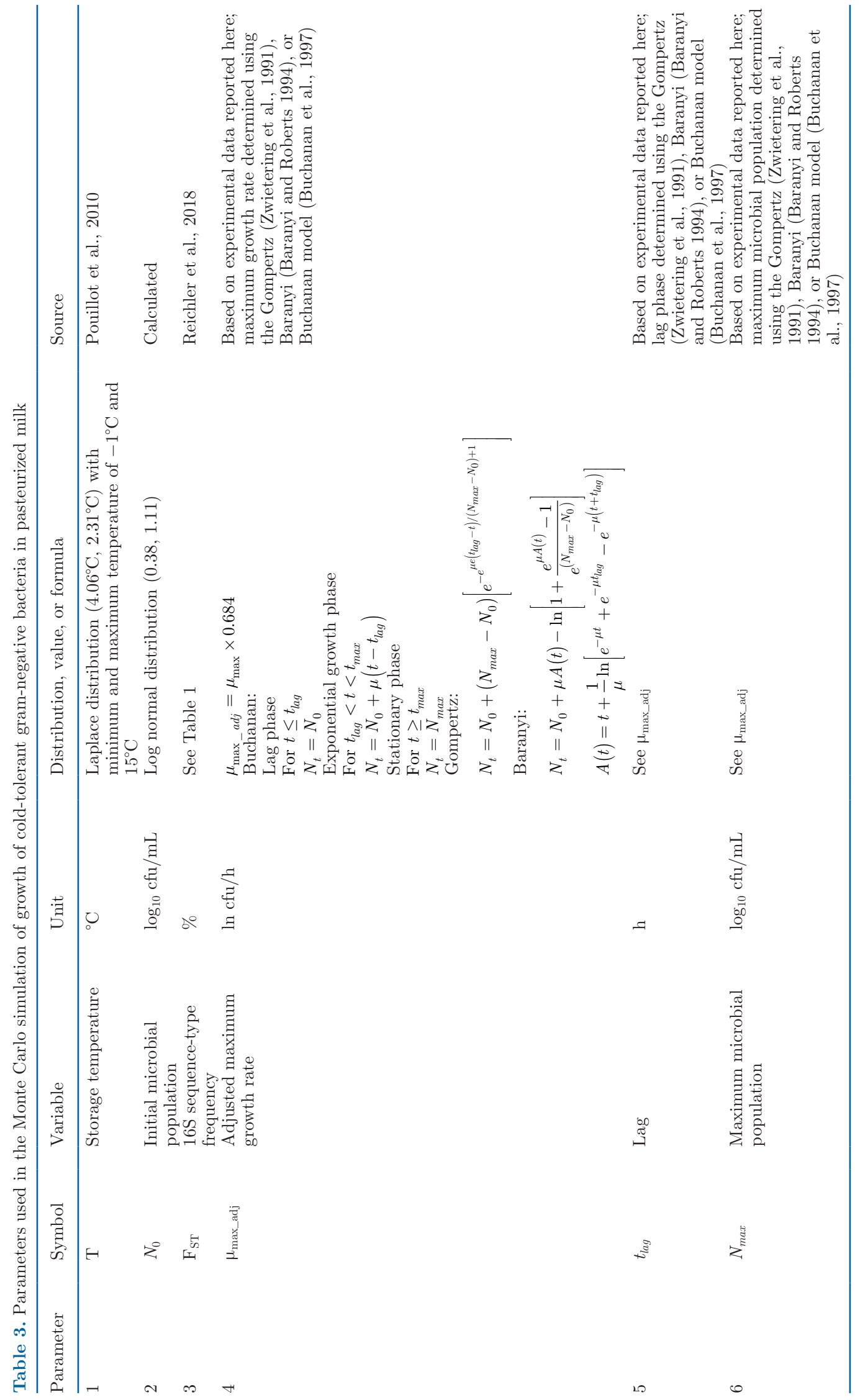




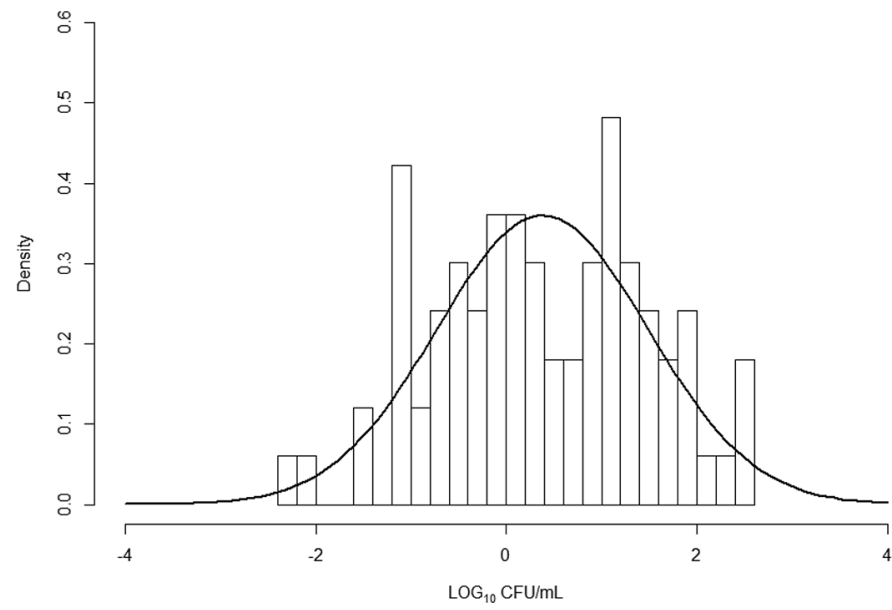

Figure 1. Initial concentrations of gram-negative bacteria in pasteurized milk extrapolated from 83 samples collected from January 2015 to June 2018. A least squares regression equation was used to extrapolate the d-1 initial concentration. Sample data below the detection limit were treated as $25 \%$ of the limit value (e.g., a detection limit of $20 \mathrm{cfu} / \mathrm{mL}$ would be counted as $5 \mathrm{cfu} / \mathrm{mL}$ ). A log normal distribution (black line overlay) was fitted to the extrapolated $d-1$ values with a mean of $0.38 \log _{10} \mathrm{cfu} / \mathrm{mL}$ and $\mathrm{SD}$ of $1.11 \log _{10} \mathrm{cfu} / \mathrm{mL}$.

Sensitivity Analysis. Five model parameters, (1) storage temperature $(T),(2)$ initial microbial concentration $\left(N_{0}\right),(3)$ frequency $\left(\mathrm{F}_{\mathrm{ST}}\right),(4)$ adjusted maximum growth rate $\left(\mu_{\text {max _adj }}\right)$, and $(5)$ lag $\left(t_{\text {lag }}\right)$, were included in the sensitivity analysis to determine the relative effects of each parameter on the percentage of containers predicted to spoil due to PPC (i.e., $>20,000$ $\mathrm{cfu} / \mathrm{mL}$ SPC and presence of PPC) on $\mathrm{d} 7$ and $\mathrm{d} 10$ of shelf life; d 7 and d 10 were selected for analyses because, if there was spoilage due to PPC, this would be captured through bacterial counts on these $2 \mathrm{~d}$, and data is available for d 7 and 10 with VSL samples for validation. Maximum microbial population $\left(N_{\max }\right)$ was not assessed for sensitivity analysis because, under the assumption that all milk should have relatively similar concentrations of nutrients, the carrying capacity of bacteria should not change, and thus minimal change in $N_{\max }$ will occur. In one-at-a-time analyses, each respective model parameter $\left(\mathrm{T}, N_{0}, \mathrm{~F}_{\mathrm{ST}}, \mu_{\text {max_adj }}\right.$, or $\left.t_{\text {lag }}\right)$ was individually increased or decreased by $20 \%, 40 \%$, and $60 \%$, while all other model parameters were kept constant. This deterministic approach allowed us to understand the model response to extreme variations of parameter inputs and to compare different parameters with the same level of deviation. For $N_{0}$ (the initial microbial concentration) values were on a $\log _{10}$ scale, so the percent reduction was applied to the log value, not the untransformed value (e.g., a $10 \%$ reduction translates into a change from $2 \log _{10}$ to $\left.1.8 \log _{10}\right)$. For $\mathrm{F}_{\mathrm{ST}}$, sensitivity analyses were conducted by removing the ST with the fastest maximum growth rate until ST that represented $20 \%, 40 \%$, and $60 \%$ of isolates were removed; for example, removal of 15 out of $125 \mathrm{ST}$ that represented the fastest growth rates removed the $20 \%$ of isolates that were assigned the fastest growth rates in the original analysis. The same analyses were conducted by removing the ST with the slowest maximum growth rate until ST that represented $20 \%, 40 \%$, and $60 \%$ of isolates were removed; for example, removal of the $51 \mathrm{ST}$ that represented the slowest growth rates removed the $20 \%$ of isolates that were assigned the slowest growth rates in the original analysis. The effect of changes to each model parameter was assessed relative to the percentage of half-gallons of milk that were predicted by the baseline model to spoil due to PPC on d 7 and $\mathrm{d} 10$.

What-If Analysis. Four what-if scenarios were used to evaluate the predicted effect of different control measures on the proportion of containers spoiled due to PPC, including (1) reducing the frequency of PPC, (2) reducing the initial concentration of organisms introduced into containers through PPC, (3) eliminating specific ST of concern, including the fastest-growing and most frequent ST, and (4) improving temperature control of fluid milk storage. For scenarios (1) through (3), different levels of change were also assessed (Table 4); henceforth these are referred to as "sub-scenarios." To determine how many additional days of shelf life different what-if scenarios would provide, we assessed the amount of storage time that was needed to reach a point where $34.32 \%$ of half-gallons showed bacteria numbers $>20,000 \mathrm{cfu} / \mathrm{mL}$, representing the percentage of half-gallons that reach this threshold by $\mathrm{d} 7$ in the baseline model (Table 4). Day 7 was chosen for assessment of additional days of shelf life because it was one of the $2 \mathrm{~d}$ (i.e., $\mathrm{d} 7$ and $\mathrm{d}$ 10) validated with data from commercial operations (i.e., VSL data), and validation assessing simulation data and VSL data resulted in closer alignment based on the test statistic for $\mathrm{d} 7$ compared with d 10.

Scenario (1), which models the effects of reducing the frequency of PPC, would represent situations where a processor would implement control strategies with different levels of effectiveness in reducing the frequency with which PPC occurs. This what-if scenario included 2 sub-scenarios, one where the frequency of contaminated containers was reduced from $100 \%$ to $50 \%$, which could represent implementation of enhanced cleaning or sanitation strategies (e.g., periodic equipment cleaning), and one where the frequency was reduced from $100 \%$ to $10 \%$, which could represent installation of new equipment (e.g., fillers) with improved sanitary design. Scenario (2), which models the effects of reducing the initial concentration of organisms introduced into containers through PPC, would represent situations 
where the frequency of contamination stayed similar, but the concentration of PPC organisms introduced would be reduced; for example, through preventative maintenance, which could remove gaskets or fillers that can harbor high concentrations of PPC organisms. Scenario (2) included sub-scenarios where the initial concentration was reduced by 1 or $3 \log _{10}$, as well as a sub-scenario that reduced initial concentration by 2 $\log _{10}$ for only $10 \%$ of containers; this sub-scenario was evaluated to determine the effect of adding an antimicrobial coating to drains. Drains were assumed to be responsible for $10 \%$ of PPC, and a previous study showed that an antimicrobial coating can reduce cell density by approximately $2 \log _{10}$ (Werner et al., 2019). Contamination with aerosolized bacteria from drains can reach milk cartons through the use of high-pressure hoses when cleaning the floors of a processing plant (Kang and Frank, 1990).

Scenario (3), which models the effects of eliminating specific ST, would reflect situations where processors implement targeted strategies to eliminate specific subtypes of PPC organisms (e.g., through application of "Seek and Destroy," as first described by Butts, 2003); the 2 sub-scenarios included here were (a) elimination of all contamination with ST 100, which had the highest growth rate, and (b) eliminating all contamination with the 2 most frequent ST (ST 13 and 9). For subscenarios (a) and (b), we also modeled 2 outcomes of the intervention, including one ("Outcome 1") where elimination of ST would render any container that would have been contaminated with the eliminated ST or ST as "uncontaminated"; this outcome would be representative of plants with one or few well-defined niches for PPC organisms that can be eliminated through Seek and Destroy. Outcome 2, by contrast, modeled a situation where containers that were contaminated, in the baseline model, with either the ST with the highest growth rate or the 2 most frequent ST, are now contaminated with one of the remaining ST. This outcome would be typical for plants where PPC is caused by many different ST; whereas Seek and Destroy may allow for elimination of specific niches, other contamination sources will remain present and would "fill in" for the ST removed through Seek and Destroy.

Scenario (4) evaluated the effect of improved temperature control on fluid milk spoilage due to PPC; this scenario could include use of temperature sensors to verify effective implementation of this intervention. Here, we truncated the temperature to $6^{\circ} \mathrm{C}$, such that the maximum temperature a product can experience is $6^{\circ} \mathrm{C}$ (simulating stringent temperature control during storage and distribution). Each half-gallon's assigned temperature was drawn from the previously described modified Laplace distribution; if the temperature drawn was $>6^{\circ} \mathrm{C}$, a new temperature would be redrawn from the distribution.

\section{RESULTS}

\section{Gram-Negative Bacteria Representatives Commonly Associated with PPC Grow Rapidly at Low Temperatures}

All 17 isolates for which cold-growth data were obtained showed $>1 \log _{10}$ growth in SMB incubated at $6^{\circ} \mathrm{C}$. Growth modeling yielded (1) estimated lag phases ranging from $<4 \mathrm{~h}$ to $34.9 \mathrm{~h},(2)$ maximum growth rates $\left(\mu_{\max }\right)$ ranging from 0.058 to $0.141 \mathrm{ln} \mathrm{cfu} / \mathrm{h}$, and (3) maximum cell density $\left(N_{\max }\right)$ ranging from 7.35 to $9.20 \log _{10} \mathrm{cfu} / \mathrm{mL}$ (Table 2). The isolate with the highest $\mu_{\max }$ was Pseudomonas grimontii, isolate FSL R10-1432. The lag phase duration and $\mu_{\max }$ of 7 Pseudomonas spp. isolates were not significantly different $(P<0.001)$ from the 10 gram-negative bacteria that were not identified as Pseudomonas spp. We identified the best-fitting growth model for each of the 17 isolates using the cold-growth data; $14 / 17$ were fitted to the Gompertz model, 3/17 were fitted to the Baranyi model, and 0/17 were fitted to the Buchanan model (Table 2).

\section{Model Output and Validation}

Initial validation efforts showed that our model overestimated both the frequency of spoilage due to PPC (i.e., percentage of containers with SPC $>20,000 \mathrm{cfu} /$ $\mathrm{mL}$ ) and mean bacterial counts at $\mathrm{d} 7$ and 10 of shelf life (Supplemental Figure S2, https://doi.org/10.7298/yth9 -zq08; Lau et al., 2021). To compensate for the observed overestimation, an adjustment factor was computed based on (1) the average $\mu_{\max }$ across all $17 \mathrm{ST}_{\text {exp growth }}$ $(0.098 \mathrm{ln} \mathrm{cfu} / \mathrm{h})$ and $(2)$ the average $\mu_{\max }$ for the VSL samples $(0.067 \mathrm{ln} \mathrm{cfu} / \mathrm{h})$. We used the obtained ratio of these $2 \mu_{\max }$ values (0.684) as a multiplier for each of the 17 experimentally obtained $\mu_{\max }$ values, yielding adjusted maximum growth rates $\left(\mu_{\text {max_adj }}\right)$ for use in the model. The $\mu_{\max \text { adj }}$ ranged from 0.040 to $0.096 \mathrm{ln}$ $\mathrm{cfu} / \mathrm{h}$ (Table 2). A Kolmogorov-Smirnov test was used to compare the distribution of simulated and observed counts (Figure 2). The Kolmogorov-Smirnov critical value for d 7 was 0.12 , and the test statistic was 0.18 $(P<0.001)$. The Kolmogorov-Smirnov critical value for d 10 was 0.11 , and the test statistic was $0.24(P<$ 0.0001). Despite the Kolmogorov-Smirnov test showing significant differences between the model output data and the observed (validation) data, we deemed the model with the utilized input parameters to be appropriate as the baseline model that could be used for 


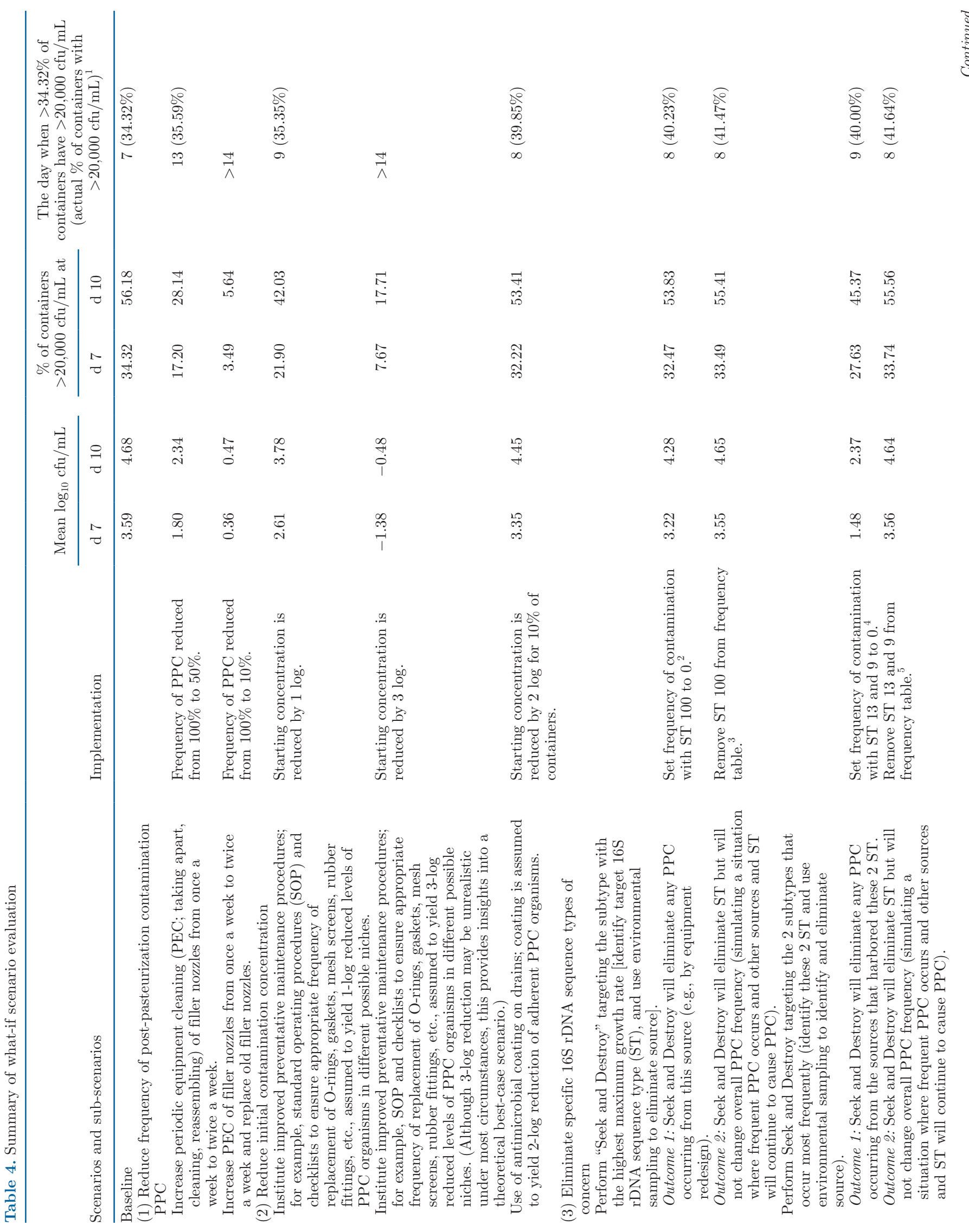


the sensitivity analyses and what-if scenario evaluation subsequently detailed. This approach is justified by the observation that differences between model predictions and observed data are minimal; for example, the mean model predicted and validation data count for $\mathrm{d} 7$ were $4.8 \log _{10} \mathrm{cfu} / \mathrm{mL}$ and $4.3 \log _{10} \mathrm{cfu} / \mathrm{mL}$, respectively, whereas the percentage of containers $>20,000 \mathrm{cfu} / \mathrm{mL}$ $\mathrm{SPC}$ at $\mathrm{d} 7$ were $66.5 \%$ and $59.1 \%$, respectively. For d 10 , the mean model predicted and validation data count were 6.3 and $6.4 \log _{10} \mathrm{cfu} / \mathrm{mL}$, respectively, whereas the percentage of containers $>20,000 \mathrm{cfu} / \mathrm{mL}$ SPC were $95.1 \%$ and $86.9 \%$, respectively. The validated model predicted the mean counts for d 7, 10, and 14 as 3.6 $\log _{10} \mathrm{cfu} / \mathrm{mL}, 4.7 \log _{10} \mathrm{cfu} / \mathrm{mL}$, and $5.8 \log _{10} \mathrm{cfu} / \mathrm{mL}$, respectively (Figure 3). The truncation on the right side of the d 10 and d 14 distributions can be explained by the ST reaching its $N_{\max }$ concentration.

\section{Adjusted Maximum Growth Rate and Storage Temperature Have the Largest Effects on Improving the Overall Average Shelf Life of Pasteurized Fluid Milk}

One-at-a-time sensitivity analyses of the 5 model input parameters $\left(\mathrm{T}, N_{0}, \mathrm{~F}_{\mathrm{ST}}, \mu_{\text {max_adj }}\right.$, and $\left.t_{\text {lag }}\right)$ indicated that $(1)$ adjusted maximum growth rate $\left(\mu_{\text {max_adj }}\right)$ and (2) storage temperature ( $\mathrm{T}$ ) had the largest effects on model outcomes, with the relative importance of these 2 parameters differing depending on whether changes were positive (i.e., an increase in temperature or an increase in adjusted maximum growth rate, both leading to increased spoilage due to PPC) or negative (i.e., a decrease in temperature or adjusted maximum growth rate). Specifically, storage temperature $(\mathrm{T})$ appeared to affect outcomes more when values were increased, whereas adjusted maximum growth rate $\left(\mu_{\text {max_adj }}\right)$ appeared to be more influential when values were decreased (Figure 4). The parameters initial microbial concentration $\left(N_{0}\right)$ and frequency $\left(\mathrm{F}_{\mathrm{ST}}\right)$ showed an approximately equal influence on outcomes but were less important than adjusted maximum growth rate $\left(\mu_{\text {max_adj }}\right)$ and storage temperature (T; Figure 4$)$. Finally, lag phase $\left(t_{\text {lag }}\right)$ appeared to have the least effect on model outcomes (Figure 4). For example, a $60 \%$ increase of lag time $\left(t_{\text {lag }}\right)$, which will lead to reduced spoilage due to PPC, resulted in a minimal decrease in percentage of containers with $>20,000 \mathrm{cfu} / \mathrm{mL}$ at d 7 from $34.32 \%$ to $31.25 \%$ (Figure 4A; Supplemental Table S1, https://doi.org/10 .7298/yth9-zq08; Lau et al., 2021), whereas a reduction in adjusted maximum growth rate $\left(\mu_{\text {max_adj }}\right)$ by $60 \%$ (which also reduces spoilage due to PPC), resulted in a substantial decrease in percentage of containers with $>20,000 \mathrm{cfu} / \mathrm{mL}$ at $\mathrm{d} 7$ from $34.32 \%$ obtained with the baseline model to $4.97 \%$ (Figure 4A; see Supplemental 
Table S1 for detailed data, Lau et al., 2021). Overall, sensitivity analysis findings were consistent regardless of whether analyses were performed using the percentage of containers with $>20,000 \mathrm{cfu} / \mathrm{mL}$ on $\mathrm{d} 7$ or $\mathrm{d} 10$ as an outcome (Figure $4 \mathrm{~A}$ and B).

\section{Conducting What-If Scenarios Can Be Used to Evaluate the Effects of Applying Interventions}

The model was used to evaluate what effects hypothetical what-if scenarios would have on predicted pasteurized fluid milk spoilage due to PPC. What-if scenarios were defined to capture possible interventions that would (1) reduce the frequency of PPC, (2) reduce the initial contamination concentration, (3) eliminate specific ST of concern, and (4) improve temperature control (Table 4). Metrics for effectiveness of interventions were the percentage of half-gallon containers with $>20,000 \mathrm{cfu} / \mathrm{mL}$ at $\mathrm{d} 7$ and 10 , and the number of days of shelf life extension. These what-if analyses identified that scenario (1), reducing the frequency of PPC, had the greatest effect on increasing the shelf life of pasteurized milk, compared with the other 3 scenarios. Reducing the frequency of contamination from $100 \%$ to $50 \%$ predicted that $17.20 \%$ and $28.14 \%$ of half-gallon containers reached $>20,000 \mathrm{cfu} / \mathrm{mL}$ on $\mathrm{d} 7$ and 10 , respectively (compared with $34.32 \%$ and $56.18 \%$ under the baseline model); reducing frequency of contamination to $10 \%$ predicted that $3.49 \%$ and $5.64 \%$ of halfgallon containers reached $>20,000 \mathrm{cfu} / \mathrm{mL}$ on $\mathrm{d} 7$ and 10, respectively. Using another sub-scenario, reducing the frequency of contaminated containers from $100 \%$ to $50 \%$ extended shelf life by $6 \mathrm{~d}$, whereas reducing the frequency to $10 \%$ increased shelf life by $>7 \mathrm{~d}$ (Table 4). By comparison, reducing the initial contamination level by 1 and $3 \log _{10}$ [scenario (2); Table 4] reduced the percentage of containers with $>20,000 \mathrm{cfu} / \mathrm{mL}$ to (1) $21.90 \%$ and $42.03 \%$ on $\mathrm{d} 7$ and 10 (for $1 \log _{10}$ reduction) and (2) $7.67 \%$ and $17.71 \%$ on $d 7$ and 10 (for $3 \log _{10}$ reduction). Importantly, reducing initial contamination levels by 1 and $3 \log _{10}$ yielded $0.82 \%$ and $28.80 \%$ of containers with starting inoculums of $<1 \mathrm{cfu} /$ container; our model was set to not allow bacterial growth in these containers, which is different from growth models that, by default, will allow for growth from levels below a single cell per container. Reducing initial contamination levels by 1 and $3 \log _{10}$ extended shelf life by 2 and $>7 \mathrm{~d}$, respectively. The effect of reducing the contamination level by $2 \log _{10}$ for $10 \%$ of containers was estimated to reduce spoilage due to PPC to $32.22 \%$ and $53.41 \%$ on d 7 and 10, respectively; this scenario simulates a "drain intervention" that reduces adhered bacteria in drains by $2 \log _{10}$ (this includes the assumption that $10 \%$ of PPC can be traced back to drains as a source).
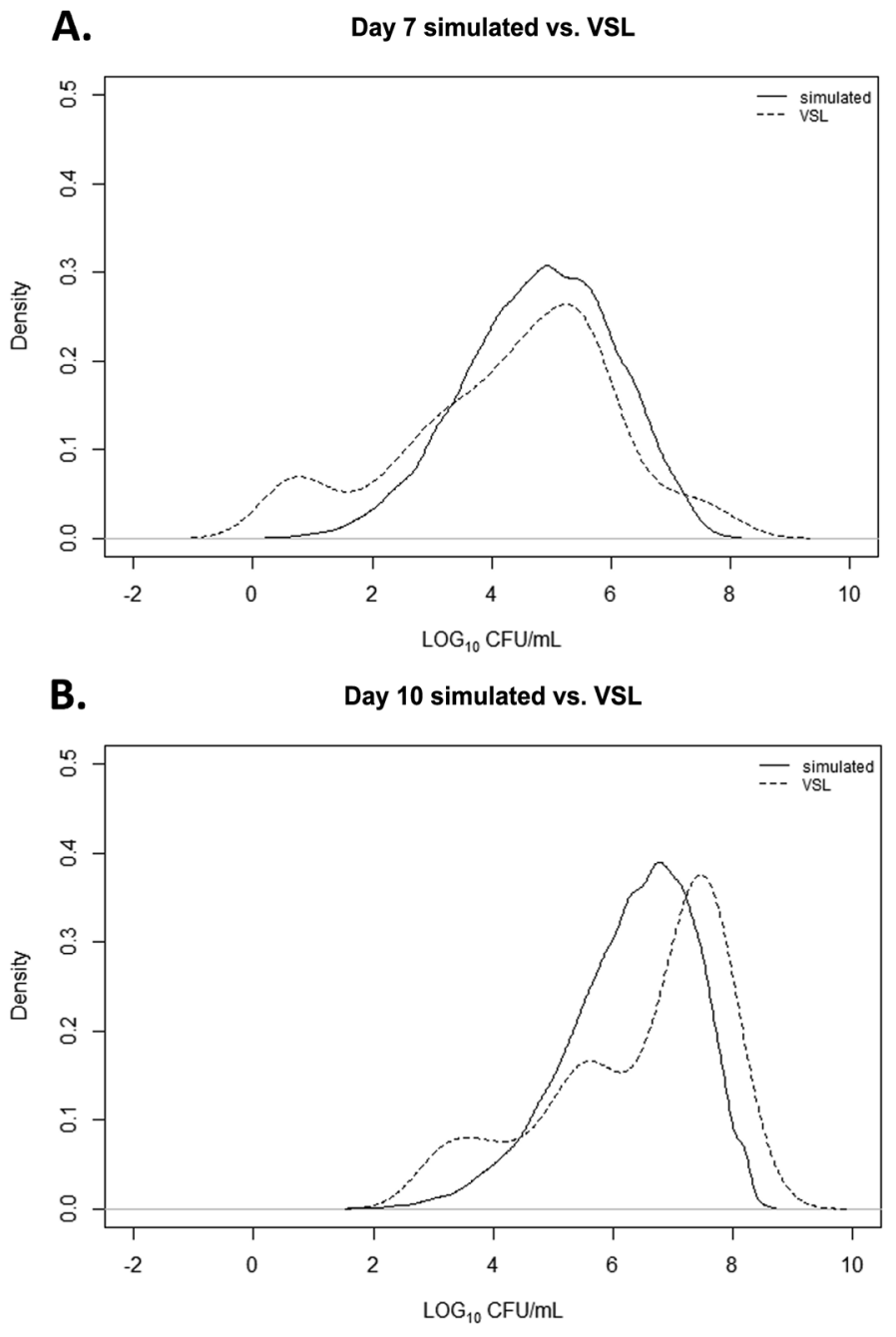

Figure 2. Density plot of the simulated concentration of postpasteurization contamination $(\mathrm{PPC})$ organisms $\left(\log _{10} \mathrm{cfu} / \mathrm{mL}\right)$ in fluid milk per half-gallon at (A) $7 \mathrm{~d}$ and (B) $10 \mathrm{~d}$ of storage at $6^{\circ} \mathrm{C}$ (solid line) and actual concentrations of PPC organisms in fluid milk per half-gallon at $7 \mathrm{~d}$ and $14 \mathrm{~d}$ of storage at $6^{\circ} \mathrm{C}$, based on commercial fluid milk samples tested as part of the Cornell University Milk Quality Improvement Program Voluntary Shelf Life Program (VSL; dashed line). In (B) a peak occurs around $8 \log _{10} \mathrm{cfu} / \mathrm{mL}$ for the simulated concentration of PPC organisms, which can be explained by the sequence type reaching its maximum microbial population $\left(N_{\max }\right)$ concentration.

Another set of interventions that were evaluated with our model were hypothetical Seek and Destroy interventions, which were designed either to target the fastest growing ST or to target the 2 most frequently isolates ST. For each of these 2 sub-scenarios, the effects of 2 possible outcomes were modeled, including (1) complete elimination of the targeted ST or ST where Seek and Destroy will completely eliminate contamination originating from these sources (therefore effectively reducing the percentage of containers with PPC), and (2) elimination of the targeted ST or ST with no change 
A.

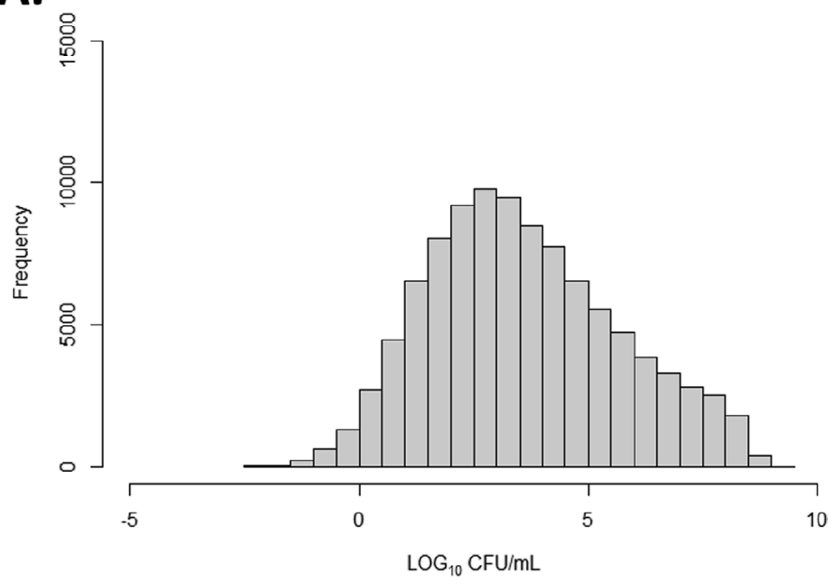

B.

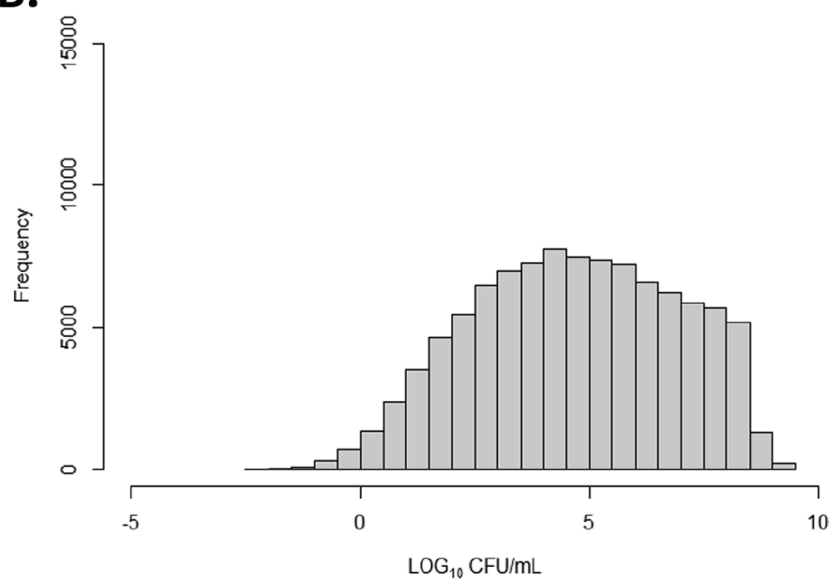

C.

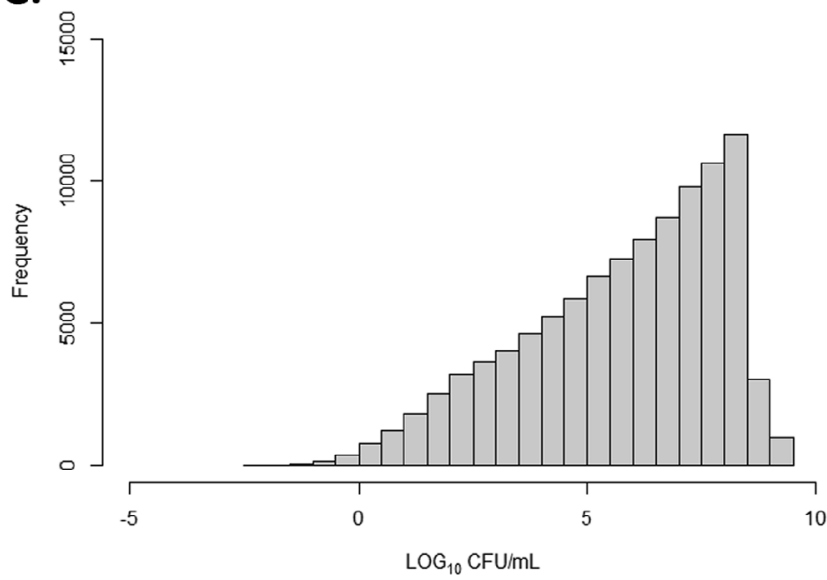

Figure 3. Histograms of the simulated concentration of post-pasteurization contamination organisms in fluid milk per half-gallon over shelf life when stored at mean temperature of $4.06^{\circ} \mathrm{C}$ at (A) $7 \mathrm{~d}$, (B) $10 \mathrm{~d}$, and (C) $14 \mathrm{~d}$. Monte Carlo simulations comprised 10,000 iterations and were based on 6 model parameters: (1) storage temperature (2) initial concentration of gram-negative bacteria in pasteurized milk $\left(N_{0}\right)$, (3) plant pasteurized milk gram-negative bacteria sequence type frequency $\left(\mathrm{F}_{\mathrm{ST}}\right)$, (4) maximum growth rate by sequence type $\left(\mu_{\text {max_adj }}\right)$, (5) lag phase by sequence type $\left(t_{\text {lag }}\right)$, and (6) maximum microbial population by sequence type $\left(N_{\max }\right)$.
Parameter

$\rightarrow$ Adjusted maximum growth rate

4. Frequency

- Initial microbial concentration

+ Lag

ه. Storage temperature

A. Day-7 sensitivity analysis

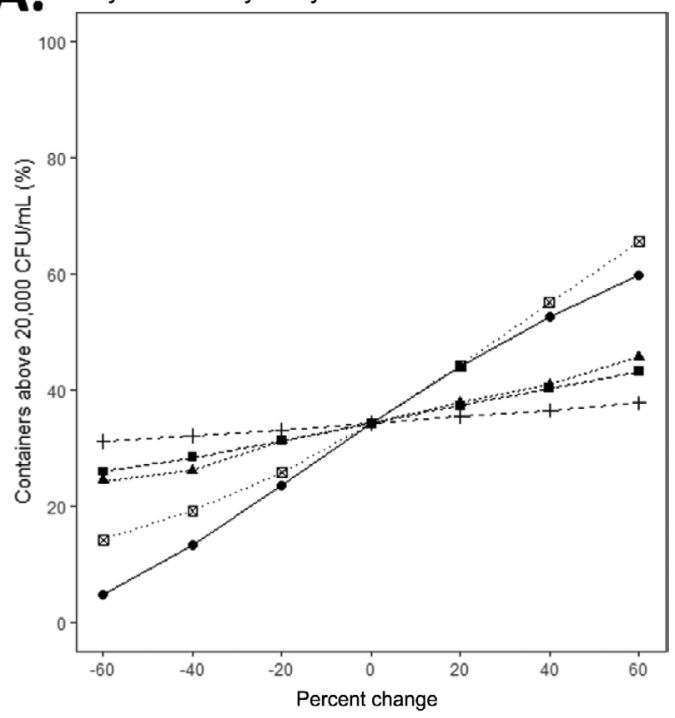

B. Day-10 sensitivity analysis

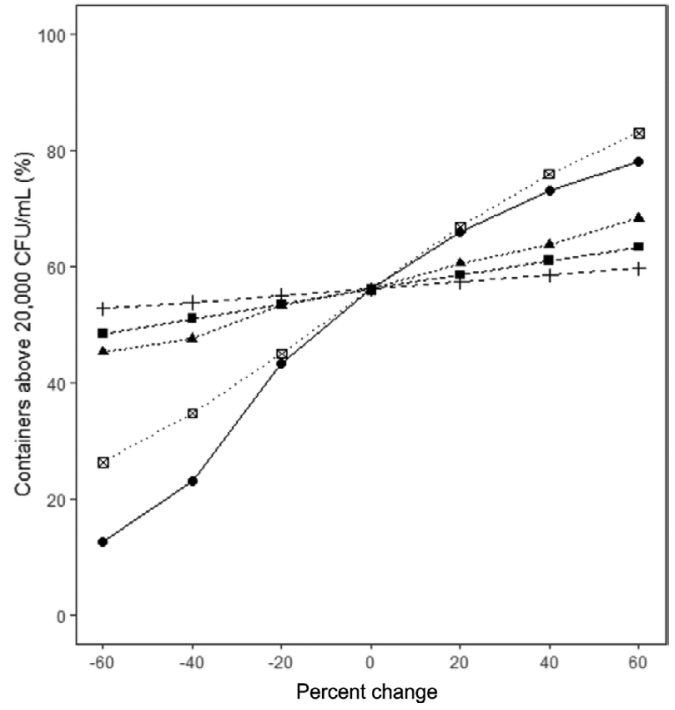

Figure 4. Sensitivity analyses assessing the effects of varying the parameters by intervals of $20 \%$ from -60 to 60 on the percent of halfgallons of fluid milk spoiled (>20,000 cfu/mL) on (A) $7 \mathrm{~d}$ and (B) 10 d of refrigerated storage for different aspects of post-pasteurization contamination (PPC) organism growth. Percent change of 0 represents the baseline model with which the other parameters were compared. Positive percent change represents a change to the parameter that will decrease shelf life or increase spoilage due to PPC. Negative percent change represents a change to the parameter that will increase shelf life or decrease spoilage due to PPC. (The results from the lag parameter were inverted to go in the same direction as the other parameters; e.g., for Figure $4 \mathrm{~A}$, the $-60 \%$ change should not be interpreted as a $60 \%$ decrease in lag. The negative percent change represents a change in the parameter that will increase shelf life and thus should be interpreted as a $60 \%$ increase in shelf life; i.e., $60 \%$ increase in lag.) 
in overall PPC frequency (simulating a situation where frequent PPC occurs, and other sources and ST will continue to cause PPC). Any of these sub-scenarios, regardless of which outcome was modeled, yielded increases in shelf life by only 1 to $2 \mathrm{~d}$ (Table 4 ). Similarly, modeling the influence of improving temperature control (in a way that would ensure that all containers would always be kept at $<6^{\circ} \mathrm{C}$ ) extended shelf life only by an estimated $2 \mathrm{~d}$ (Table 4 ).

\section{DISCUSSION}

Although fluid milk spoilage due to PPC is well documented as a major challenge, not many data-driven tools are available to the dairy industry to help assess and identify appropriate and effective PPC interventions. To address this gap, we collected data on the growth characteristics of gram-negative bacteria associated with PPC, which were subsequently leveraged to develop a model that simulates pasteurized fluid milk spoilage due to PPC by predicting the concentration of PPC organisms in fluid milk over shelf life. Sensitivity analysis showed that storage temperature $(\mathrm{T})$ and adjusted maximum growth rate $\left(\mu_{\text {max_adj }}\right)$ had the greatest influence on the percentage of milk containers that showed bacterial counts above the threshold of 20,000 $\mathrm{cfu} / \mathrm{mL}$. Importantly, the developed model allowed for rapid simulation of what-if scenarios that can be used to evaluate the effects of different interventions on fluid milk shelf life; among the interventions modeled here, those that reduced the frequency of PPC contamination showed the greatest influence on shelf life.

\section{A Wide Range of Gram-Negative Bacteria Can Grow in Skim Milk Broth at $6^{\circ} \mathrm{C}$}

The 17 isolates of gram-negative bacteria chosen to represent bacteria associated with PPC showed a wide range of lag phase duration. The selected isolates had estimated lag phase durations that ranged between less than $4 \mathrm{~h}$ and $34.9 \mathrm{~h}$ at $6^{\circ} \mathrm{C}$. Among the 7 Pseudomonas spp. isolates characterized, estimated lag phase duration ranged from $<4$ to $25.5 \mathrm{~h}$. This is consistent with reports from previous studies; for example, Chen et al. (2011) reported a lag phase of $9.4 \mathrm{~h}$ for P. fluorescens in whole UHT milk at $7^{\circ} \mathrm{C}$, whereas Lin et al. (2016) reported a lag phase of $29.5 \mathrm{~h}$ for $P$. fluorescens in lowfat $(1 \%)$ UHT milk at $4^{\circ}$ C. Similarly, Stevenson et al. (2003) found that $P$. fragi in UHT skim milk at $4^{\circ} \mathrm{C}$ had an estimated lag phase duration of less than 24 h, whereas the lag phase duration for 4 different $P$. fluorescens ranged from 9.36 to $48.96 \mathrm{~h}$. To allow us to compare our findings to those from these similar previous studies, we adjusted the previously reported lag phases for Pseudomonas spp. (Stevenson et al., 2003; Chen et al., 2011; Lin et al., 2016) from the original study temperature (e.g., $4^{\circ} \mathrm{C}$ for Stevenson et al., 2003), to $6^{\circ} \mathrm{C}$ (the temperature we used in our growth experiments), using Ratkowsky's square root model (Ratkowsky et al., 1982); we found that the adjusted lag phase durations ranged between 0 and $31.6 \mathrm{~h}$, which is comparable to results from our study. The remaining 10 non-Pseudomonas isolates that were tested in our study showed lag phase durations between $<4$ and $34.9 \mathrm{~h}$. Unlike the growth data for Pseudomonas spp., growth data in milk for dairy-related non-Pseudomonas species is lacking in the literature. Although we observed differences in the duration of lag phases for different isolates, all of these recorded lag phases are considered short in relation to the duration of a typical milk shelf life; for example, shelf life of HTST-pasteurized milk with PPC ranges from 10 to $14 \mathrm{~d}$ at $6^{\circ} \mathrm{C}$ (Reichler et al., 2018).

Overall growth rates for the 17 gram-negative bacteria most commonly associated with PPC were between 0.058 to $0.141 \mathrm{ln} \mathrm{cfu} / \mathrm{h}$ at $6^{\circ} \mathrm{C}$, which represents doubling times ranging from 4.93 to $11.8 \mathrm{~h}$. Of all isolates tested, P. grimontii ST 100 had the highest $\mu_{\max }$, at $0.141 \mathrm{ln} \mathrm{cfu} / \mathrm{h}$. The 2 most frequent $\mathrm{ST}$ in the data set, Pseudomonas poae and P. fragi, ST 9 and 13, had $\mu_{\max }$ of 0.107 and $0.100 \mathrm{ln} \mathrm{cfu} / \mathrm{h}$, respectively. These growth rates are lower compared with the growth rates reported by Stevenson et al. (2003), who found that in UHT skim milk at $4^{\circ} \mathrm{C}, P$. fragi had a growth rate of approximately $0.136 \mathrm{ln} \mathrm{cfu} / \mathrm{mL}$, and 4 P. fluorescens isolates had growth rates in the range of 0.120 to $0.142 \mathrm{ln} \mathrm{cfu} /$ $\mathrm{mL}$. Similarly lower growth rates were determined for all 7 Pseudomonas spp. (mean of $0.107 \mathrm{ln} \mathrm{cfu} / \mathrm{h}$, range of 0.086-0.141 ln cfu/h) and 10 non-Pseudomonas spp. isolates (mean of $0.092 \mathrm{ln} \mathrm{cfu} / \mathrm{h}$, range of $0.058-0.133$ ln $\mathrm{cfu} / \mathrm{h}$ ) characterized during this study. More rapid growth rates of Pseudomonas spp. compared with nonPseudomonas spp. are consistent with prior studies that found that Pseudomonas spp. are more frequently responsible for milk spoilage compared with other gramnegative organisms (i.e., Enterobacteriaceae; Ternström et al., 1993; Ranieri and Boor, 2009).

\section{PPC Models Using Growth Parameters from Pure Culture in Skim Milk Broth Require an Adjustment Factor to Better Predict PPC}

Initial validation of the PPC model developed here showed that the simulation model consistently overestimated the percentage of spoiled half-gallons on $\mathrm{d} 7$ and 10 of shelf life. We reasoned that this was most likely due to the fact that growth data were collected in SMB, which may allow for more rapid growth than HTST milk. For example, presence of residual lacto- 
peroxidase in HTST milk (which would be absent from SMB, which has undergone substantially harsher heat treatment than HTST milk) could partially inhibit growth of bacteria introduced by PPC (Reiter and Härnulv, 1984; Munsch-Alatossava et al., 2018). Lactoperoxidase plays a bactericidal role due to its ability to form oxidized compounds with antimicrobial properties (Munsch-Alatossava et al., 2018). Alternatively, or additionally, bacterial growth in actual commercial milk with PPC may also be slower compared with the growth determined in this study, since growth data in SMB were collected in pure culture, whereas commercial milk samples are likely contaminated with multiple bacterial subtypes. This is supported by Reichler et al. (2018), who found that, among 280 HTST fluid milk samples from 10 different processing plants, samples that showed $\mathrm{SPC}>20,000 \mathrm{cfu} / \mathrm{mL}$ in at least one day of shelf life had a mean of 8.5 different bacterial isolates (based on $16 \mathrm{~S}$ sequencing). Another study that collected pasteurized milk samples from 4 processing plants also reported considerable genetic diversity of Pseudomonas spp. within fluid milk products, which further supports that PPC may often represent contamination with multiple strains (Dogan and Boor, 2003). Competition for limited nutrients or production of inhibitory substances by some strains (Gram et al., 2002) can explain why growth in pure cultures is faster than bacterial growth in real-life milk samples. Similarly, Xu (2021) emphasized the importance of interactions in mixed cultures, including possible coexisting interactions, where species may slow one another's growth. To address the fact that the initial model overestimated bacterial growth, we calculated an adjustment factor that adjusted the growth rates determined in SMB (0.098 ln cfu/h, which corresponds to a doubling time of $7.1 \mathrm{~h}$ ) to the growth rates that are based on available growth data expected in pasteurized milk $(0.067 \mathrm{ln} \mathrm{cfu} / \mathrm{h}$, which represents a doubling time of $10.3 \mathrm{~h}$ ). Applying the adjustment factor results in a change in the test statistic of the Kolmogorov-Smirnov test from 0.65 and 0.40 for the initial model without the adjustment factor, to 0.18 and 0.24 for the model with the adjustment factor, for $\mathrm{d} 7$ and 10, respectively. Once the adjustment factor was implemented in the PPC model, the model was able to more accurately predict the percentage of spoiled half-gallons for commercial milk containers.

Importantly, adjustment factors have been used in previous studies to account for certain limitations in predictive models and to tune models to predict observed real-world outcomes. For example, in a risk assessment of Listeria monocytogenes in ready-to-eat foods, researchers used an adjustment factor to account for the variability of the parameters that influence the relationship between the dose and illness severity (FDA,
2003); this adjustment factor was necessary because the lethal dose was determined using mortality data from mice studies, and adjustment was made based on Centers for Disease Control and Prevention estimates of annual death rates (FDA, 2003). Another adjustment factor was used in the risk assessment to account for overestimation of $L$. monocytogenes prevalence in ready-to-eat foods from older studies compared with recent studies that could be a result of higher actual contamination levels or nonrepresentative sampling (FDA, 2003). These adjustment factors are used to account for studies conducted with experimental animals and the limited amount of data available, respectively. Although these previous applications of adjustment factors validate our use of an adjustment factor, future experiments to identify the reason for why SMB-based growth parameters apparently overestimate fluid milk spoilage will be important, particularly as they may help identify improvements that may be needed for future models (e.g., inclusion of multiple strain interactions instead of the simplifying assumption that a given container will be contaminated with only $1 \mathrm{ST}$ ).

\section{Adjusted Maximum Growth Rate and Storage Temperature Have the Greatest Influence on Predicted Concentrations of Bacteria Associated with PPC in Fluid Milk Over Shelf Life}

Sensitivity analysis indicated that adjusted maximum growth rate $\left(\mu_{\text {max_adj }}\right)$ and storage temperature (T) have the strongest effects on predicted percentage of containers spoiled due to PPC on d 7 and 10 of shelf life, suggesting that accurate and sufficient data for these 2 parameters are important for the type of spoilage models developed here. The importance of maximum growth rate for estimating microbial spoilage and bacterial growth was also demonstrated by Buehler et al. (2018) using the Monte Carlo simulation model they developed to predict pasteurized fluid milk spoilage due to psychrotolerant spore-forming bacteria. Sensitivity analysis of a model that was developed to predict growth of L. monocytogenes on cheese curds also found that maximum growth rate was among the most influential parameters (Couvert et al., 2010). Similarly, in a publication that reported a general framework for quantitative microbial food safety risk assessment (McNab, 1998), maximum growth rate (designated as "growth rate after treatment") was consistently found to be one of the top 3 ranked parameters across sensitivity analyses conducted for different specific scenarios. Likewise, previous studies have also found storage temperature to have a considerable effect on the output of different microbial risk assessment models. For example, a Monte Carlo simulation model for 
bacterial spoilage of fluid milk developed by Schaffner et al. (2003) predicted that decreasing storage temperature from $6.5^{\circ} \mathrm{C}$ to $4.4^{\circ} \mathrm{C}$ resulted in a reduction of spoilage (defined as samples exceeding $10^{7} \mathrm{cfu} / \mathrm{mL}$ ) due to growth of psychrotolerant organisms from $67 \%$ to $28 \%$ by d 14 . Similarly, the Monte Carlo simulation model for fluid milk spoilage due to psychrotolerant spore-formers, developed by Buehler et al. (2018), predicted that reducing refrigeration temperature from $6^{\circ} \mathrm{C}$ to $4^{\circ} \mathrm{C}$ would result in a reduction of spoilage at d 21 (defined as samples exceeding 20,000 cfu/mL) from $66 \%$ to $9 \%$. The sensitivity analysis and previous studies suggest a need to place more emphasis on gathering more accurate data on maximum growth rate and storage temperature when using models to predict microbial growth.

\section{What-If Scenarios Can Be Used to Assess the Effects of Different Interventions on Shelf Life}

The model developed here provided an opportunity to run different "what-if" (or scenario) analyses; these analyses provide an opportunity to assess the influence different intervention strategies may have on product shelf life, potentially helping industry with decisionmaking. The what-if analyses we conducted indicated that reducing the frequency of PPC contamination could substantially extend the shelf life of pasteurized fluid milk (e.g., increase in shelf life by $6 \mathrm{~d}$ if PPC frequency is reduced from $100 \%$ to $50 \%$ ). Possible interventions that would be expected to reduce the frequency of contamination would be implementation of enhanced periodic equipment cleaning procedures on key equipment responsible for PPC, such as filler nozzles, or replacement of equipment or equipment components with more hygienic and easer-to-clean counterparts (e.g., replacement of poorly designed fillers, replacement of difficult-to-clean filler nozzles). The potential positive effects of these types of interventions are supported by Reichler et al. (2020) and Ralyea et al. (1998), who showed that an improved preventative maintenance program targeting rubber parts of a specific filler decreased the frequency of PPC in fluid milk containers. Additionally, Murphy et al. (2021) found that having well-designed cleaning and sanitation programs, along with appropriate training, are among the top factors necessary to reduce PPC.

Reducing the initial concentration of PPC organisms was also predicted to substantially extend the shelf life of fluid milk if reductions in initial PPC contamination levels were large (e.g., a $3 \log _{10}$ reduction increased shelf life by $>7 \mathrm{~d}$, whereas a $1 \log _{10}$ reduction increased shelf life by only $2 \mathrm{~d}$ ). Although a $3 \log _{10}$ reduction in initial concentration may be unrealistic under most circumstances, this analysis provides a best-case scenario for the effects of interventions that reduce initial PPC contamination levels. Interventions that decrease initial contamination levels may include instituting improved preventative maintenance procedures such as using standard operating procedures and checklists to ensure appropriate frequency of replacement of equipment parts such as O-rings, gaskets, mesh screens, and rubber fittings. Although very limited data on actual effects of specific interventions on initial PPC levels are available, one previous study did indicate that improved inspection and cleaning, as well as preventative maintenance programs, can increase the reliability of a pizza processing line and thus reduce the frequency of failures due to equipment and lead to improvement in product quality (Tsarouhas, 2007). Importantly, a quality cost model for processing plants developed by Zugarramurdi et al. (2007) also indicated that implementation of a quality assurance plan and preventative maintenance, including replacement and maintenance of equipment parts, are appropriate and economically viable strategies to improve product quality.

Although interventions that reduce frequency and levels of PPC contamination were shown to have substantial effects on enhancing average fluid milk shelf life, other strategies tested in what-if scenarios were less effective at extending shelf life. For example, eliminating specific spoilage organisms or organism sources was predicted to extend shelf life by only 1 or $2 \mathrm{~d}$ (assuming that these interventions would not decrease PPC levels or frequency). Even with the limited effects identified by our model, Seek and Destroy-type strategies to eliminate sources of PPC could still be valuable, if these efforts are able to decrease PPC levels or frequency. For example, previous studies have shown that Seek and Destroy interventions can successfully reduce L. monocytogenes contamination of food products from environmental sources (Malley et al., 2015). A what-if scenario also suggested that ensuring improved temperature controls (defined here as ensuring that no fluid milk containers would be exposed to $>6^{\circ} \mathrm{C}$ ) extended shelf life by only $2 \mathrm{~d}$. This represents a potentially important finding, in part because temperature is one of the many food quality indicators (e.g., gas production, $\mathrm{pH}$ change, humidity) that can be targeted using intelligent packaging (Fuertes et al., 2016; Yousefi et al., 2019). For example, Ellouze and Augustin (2010) evaluated a biological time-temperature indicator that could successfully be used as a quality and safety indicator for ground beef and spiced cooked chicken slices under modified atmosphere across shelf life. Importantly, although our data suggested that limited average shelf life enhancement could be achieved by assuring product distribution at $<6^{\circ} \mathrm{C}$, future work could use our model 
to evaluate different temperature control strategies and their effects on shelf life. Influence of time-temperature indicators could also be more pronounced if the baseline temperature distribution included more abusive temperatures than the baseline used in our model. Importantly, our analysis only assessed spoilage due to PPC and did not assess other potential benefits of this type of indicators, such as reduced growth of $L$. monocytogenes, which represents a food safety hazard for which improved temperature control has been well established to reduce food safety risks (Walker et al., 1990; Chan and Wiedmann, 2008).

Although the what-if analyses conducted here provide initial insights on the effects of various intervention strategies on fluid milk shelf life, the model developed here has some limitations that will need to be addressed to enhance its value, particularly as a decision-support tool for industry. Namely, although the model developed here provides the ability to assess the potential effects of different interventions on fluid milk shelf life, additional features to facilitate decision-making should be incorporated; for example, incorporation of a costbenefit analysis module would help industry assess the economic feasibility and return on investment for different interventions. Additionally, an alternative approach can be used for the interpretation of containers assigned an initial concentration less than 1 cfu per half-gallon. Concentrations below 1 cfu per half-gallon can be interpreted as probabilities; for example, if the assigned concentration was $0.1 \mathrm{cfu}$ per half-gallon, that container would have a $10 \%$ probability of containing 1 cfu. However, this interpretation would require a change to the model structure, a process of reassigning the initial concentration with at least 1 cfu per halfgallon, and would increase the complexity of the model. Importantly, the model developed here only considers fluid milk spoilage due to PPC, yet contamination with gram-positive spore-forming bacteria can also lead to spoilage later in shelf life, which should be considered when assessing potential intervention strategies for potential influence on shelf life. For example, 2 intervention strategies evaluated here, reducing frequency of PPC from $100 \%$ to $10 \%$ and reducing the initial contamination by $3 \log _{10}$, predicted that shelf life would be extended by greater than $7 \mathrm{~d}$. When evaluating the what-if scenarios that extend shelf life by greater than $7 \mathrm{~d}$, it would be advisable to evaluate the effects using both the current model that predicts spoilage by PPC and the previously developed spoilage model (Buehler et al., 2018) that predicts spoilage by aerobic psychrotolerant spore-formers. A future combined model would be valuable to evaluate the effects of both gram-positive spore-forming bacteria and PPC organisms.

\section{CONCLUSIONS}

Overall, the model developed here, along with other models discussed, not only represents a starting point for digital tools to help industry identify appropriate approaches for enhancing fluid milk quality, but also represents a blueprint for the type of decision-support tools that can be developed and applied to other dairy products. Importantly, these types of tools will allow for more cost-effective approaches to identify appropriate shelf life extension strategies and will reduce the need for expensive field trials. Finally, the tools developed here can also be used to estimate shelf life of fluid milk and ultimately other dairy products, which provide opportunities for improved shelf life labeling, including dynamic shelf life labeling.

\section{ACKNOWLEDGMENTS}

Funding for this project was provided by the Foundation for Food and Agriculture Research (FFAR, Washington, DC; award no. CA18-SS-0000000206) and by the New York State Milk Promotion Advisory Board (Albany, NY), which funds the VSL program. The authors thank the students, faculty, and staff of the Cornell University Milk Quality Improvement Program (Ithaca, NY), with special thanks to Samuel Reichler. The authors have not stated any conflicts of interest.

\section{REFERENCES}

Alles, A. A., M. Wiedmann, and N. H. Martin. 2018. Rapid detection and characterization of postpasteurization contaminants in pasteurized fluid milk. J. Dairy Sci. 101:7746-7756. https://doi.org/ 10.3168/jds.2017-14216.

Arnold, T., and J. W. Emerson. 2013. dgof: Discrete Goodness-ofFit Tests. Accessed Nov. 23, 2020. https://cran.r-project.org/web/ packages/dgof/dgof.pdf.

Baranyi, J., and T. A. Roberts. 1994. A dynamic approach to predicting bacterial growth in food. Int. J. Food Microbiol. 23:277-294. https://doi.org/10.1016/0168-1605(94)90157-0.

Baty, F., and M. Delignette-Muller. 2017. nlsMicrobio: Data sets and nonlinear regression models dedicated to predictive microbiology. Accessed Nov. 23, 2021. https://cran.r-project.org/web/packages/ nlsMicrobio/nlsMicrobio.pdf.

Baty, F., C. Ritz, S. Charles, M. Brutsche, J.-P. Flandrois, and M.-L. Delignette-Muller. 2015. A toolbox for nonlinear regression in R: The package nlstools. J. Stat. Softw. 66:1-21. https://doi.org/10 $.18637 /$ jss.v066.i05.

Buchanan, R. L., R. C. Whiting, and W. C. Damert. 1997. When is simple good enough: A comparison of the Gompertz, Baranyi, and three-phase linear models for fitting bacterial growth curves. Food Microbiol. 14:313-326. https://doi.org/10.1006/fmic.1997.0125.

Buehler, A. J., N. H. Martin, K. J. Boor, and M. Wiedmann. 2018. Psychrotolerant spore-former growth characterization for the development of a dairy spoilage predictive model. J. Dairy Sci. 101:6964-6981. https://doi.org/10.3168/jds.2018-14501.

Butts, J. 2003. Seek \& destroy: Identifying and controlling Listeria monocytogenes growth niches. Accessed May 15, 2021. https:// www.food-safety.com/articles/4802-seek-destroy-identifying-and -controlling-listeria-monocytogenes-growth-niches. 
Buzby, J. C., H. Farah-Wells, and J. Hyman. 2014. The estimated amount, value, and calories of postharvest food losses at the retail and consumer levels in the United States. USDA-ERS Economic Information Bulletin Number 121.

Chan, Y. C., and M. Wiedmann. 2008. Physiology and genetics of Listeria monocytogenes survival and growth at cold temperatures. Crit. Rev. Food Sci. Nutr. 49:237-253. https://doi.org/10.1080/ 10408390701856272.

Chen, T. R., Q. K. Wei, and Y. J. Chen. 2011. Pseudomonas spp. and Hafnia alvei growth in UHT milk at cold storage. Food Control 22:697-701. https://doi.org/10.1016/j.foodcont.2010.10.004.

Couvert, O., A. Pinon, H. Bergis, F. Bourdichon, F. Carlin, M. Cornu, C. Denis, N. Gnanou Besse, L. Guillier, E. Jamet, E. Mettler, V. Stahl, D. Thuault, V. Zuliani, and J.-C. Augustin. 2010. Validation of a stochastic modelling approach for Listeria monocytogenes growth in refrigerated foods. Int. J. Food Microbiol. 144:236-242. https://doi.org/10.1016/j.ijfoodmicro.2010.09.024.

Dogan, B., and K. J. Boor. 2003. Genetic diversity and spoilage potentials among Pseudomonas spp. isolated from fluid milk products and dairy processing plants. Appl. Environ. Microbiol. 69:130-138. https://doi.org/10.1128/AEM.69.1.130-138.2003.

Ellouze, M., and J. C. Augustin. 2010. Applicability of biological time temperature integrators as quality and safety indicators for meat products. Int. J. Food Microbiol. 138:119-129. https://doi.org/10 .1016/j.ijfoodmicro.2009.12.012.

FAO. 2010. Greenhouse gas emissions from the dairy sector: A life cycle assessment. UN FAO.

FAO. 2019. The State of Food and Agriculture 2019. Moving forward on food loss and waste reduction. UN FAO.

FDA. 2003. Quantitative assessment of relative risk to public health from foodborne Listeria monocytogenes among selected categories of ready-to-eat foods. Accessed Nov. 23, 2021. https://www.fda .gov/media/124721/download.

FDA. 2019. Standards for grade "A" milk and/or milk products. Pages 32-35 in Grade "A" Pasteurized Milk Ordinance. US Department of Health and Human Services, Public Health Service.

Fuertes, G., I. Soto, R. Carrasco, M. Vargas, J. Sabattin, and C. Lagos. 2016. Intelligent packaging systems: Sensors and nanosensors to monitor food quality and safety. J. Sens. 2016:4046061. https:/ /doi.org/10.1155/2016/4046061.

Garrido-Sanz, D., J. P. Meier-Kolthoff, M. Goker, M. Martin, R. Rivilla, and M. Redondo-Nieto. 2016. Genomic and genetic diversity within the Pseudomonas fluorescens complex. PLoS One 11:e0150183. https://doi.org/10.1371/journal.pone.0150183.

Gram, L., L. Ravn, M. Rasch, J. B. Bruhn, A. B. Christensen, and M. Givskov. 2002. Food spoilage - Interactions between food spoilage bacteria. Int. J. Food Microbiol. 78:79-97. https://doi.org/10 .1016/S0168-1605(02)00233-7.

Gruetzmacher, T. J., and R. L. Bradley Jr.. 1999. Identification and control of processing variables that affect the quality and safety of fluid milk. J. Food Prot. 62:625-631. https://doi.org/10.4315/ 0362-028X-62.6.625.

Hoover, D. 2017. Estimating quantities and types of food waste at the city level. National Resources Defense Council.

Kang, Y.-J., and J. F. Frank. 1990. Characteristics of biological aerosols in dairy processing plants. J. Dairy Sci. 73:621-626. https:// doi.org/10.3168/jds.S0022-0302(90)78712-7.

Lau, S., A. Trmcic, N. H. Martin, M. Wiedmann, and S. I. Murphy. 2021. Development of a Monte Carlo simulation model to predict pasteurized fluid milk spoilage due to post-pasteurization contamination with gram-negative bacteria_Supplemental Material. https: //doi.org/10.7298/yth9-zq08.

Lin, H., M. Shavezipur, A. Yousef, and F. Maleky. 2016. Prediction of growth of Pseudomonas fluorescens in milk during storage under fluctuating temperature. J. Dairy Sci. 99:1822-1830. https://doi .org/10.3168/jds.2015-10179.

Malley, T. J. V., J. Butts, and M. Wiedmann. 2015. Seek and Destroy Process: Listeria monocytogenes process controls in the ready-toeat meat and poultry industry. J. Food Prot. 78:436-445. https:// doi.org/10.4315/0362-028X.JFP-13-507.
Martin, N. H., K. J. Boor, and M. Wiedmann. 2018. Symposium review: Effect of post-pasteurization contamination on fluid milk quality. J. Dairy Sci. 101:861-870. https://doi.org/10.3168/jds $.2017-13339$

Martin, N. H., N. Carey, S. Murphy, D. Kent, J. Bang, T. Stubbs, M. Wiedmann, and R. Dando. 2016. Exposure of fluid milk to LED light negatively affects consumer perception and alters underlying sensory properties. J. Dairy Sci. 99:4309-4324. https://doi.org/10 $.3168 /$ jds.2015-9603.

Martin, N. H., N. R. Carey, S. C. Murphy, M. Wiedmann, and K. J. Boor. 2012. A decade of improvement: New York State fluid milk quality. J. Dairy Sci. 95:7384-7390. https://doi.org/10.3168/jds .2012-5767.

Mazerolle, M. 2020. AICcmodavg: Model selection and multimodel inference based on (Q)AIC(c). Accessed Nov. 23, 2021. https:// cran.r-project.org/web/packages/AICcmodavg/AICcmodavg.pdf.

McNab, W. B. 1998. A general framework illustrating an approach to quantitative microbial food safety risk assessment. J. Food Prot. 61:1216-1228. https://doi.org/10.4315/0362-028X-61.9.1216.

Munsch-Alatossava, P., O. Gursoy, P. M. Lorilla, J.-P. Gauchi, and T. Alatossava. 2018. Chapter 15: Antibacterial effects and modes of action of the activated lactoperoxidase system (LPS), of $\mathrm{CO}_{2}$ and $\mathrm{N}_{2}$ gas as food-grade approaches to control bovine raw milk-associated bacteria. Pages 519-541 in Food Control and Biosecurity. A. M. Holban and A. M. Grumezescu, ed. Academic Press.

Murphy, S. I., S. J. Reichler, N. H. Martin, K. J. Boor, and M. Wiedmann. 2021. Machine learning and advanced statistical modeling can identify key quality management practices that affect postpasteurization contamination of fluid milk. J. Food Prot. 84:14961511. https://doi.org/10.4315/JFP-20-431.

Pouillot, R., M. B. Lubran, S. C. Cates, and S. Dennis. 2010. Estimating parametric distributions of storage time and temperature of ready-to-eat foods for US households. J. Food Prot. 73:312-321. https://doi.org/10.4315/0362-028X-73.2.312.

R Core Team. 2019. R: A language and environment for statistical computing. R Foundation for Statistical Computing.

Ralyea, R. D., M. Wiedmann, and K. J. Boor. 1998. Bacterial tracking in a dairy production system using phenotypic and ribotyping methods. J. Food Prot. 61:1336-1340. https://doi.org/10.4315/ 0362-028X-61.10.1336.

Ranieri, M. L., and K. J. Boor. 2009. Short communication: Bacterial ecology of high-temperature, short-time pasteurized milk processed in the United States. J. Dairy Sci. 92:4833-4840. https:// doi.org/10.3168/jds.2009-2181.

Ratkowsky, D. A., J. Olley, T. A. McMeekin, and A. Ball. 1982. Relationship between temperature and growth rate of bacterial cultures. J. Bacteriol. 149:1-5. https://doi.org/10.1128/jb.149.1.1-5 1982.

Reichler, S. J., S. I. Murphy, A. W. Erickson, N. H. Martin, A. B. Snyder, and M. Wiedmann. 2020. Interventions designed to control postpasteurization contamination in high-temperature, short-timepasteurized fluid milk processing facilities: A case study on the effect of employee training, clean-in-place chemical modification, and preventive maintenance programs. J. Dairy Sci. 103:75697584. https://doi.org/10.3168/jds.2020-18186.

Reichler, S. J., A. Trmcic, N. H. Martin, K. J. Boor, and M. Wiedmann. 2018. Pseudomonas fluorescens group bacterial strains are responsible for repeat and sporadic postpasteurization contamination and reduced fluid milk shelf life. J. Dairy Sci. 101:7780-7800. https://doi.org/10.3168/jds.2018-14438.

Reiter, B., and G. Härnulv. 1984. Lactoperoxidase antibacterial system: Natural occurrence, biological functions and practical applications. J. Food Prot. 47:724-732. https://doi.org/10.4315/0362 $-028 \mathrm{X}-47.9 .724$

Schaffner, D., S. Duffy, R. Montville, and S. Smith. 2003. Monte Carlo simulation of the shelf life of pasteurized milk as affected by temperature and initial concentration of spoilage organisms. Food Prot. Trends 23:1014-1021.

Schröder, M. J. A. 1984. Origins and levels of post pasteurization contamination of milk in the dairy and their effects on keep- 
ing quality. J. Dairy Res. 51:59-67. https://doi.org/10.1017/ S0022029900023323.

Stevenson, R. G., M. T. Rowe, G. B. Wisdom, and D. Kilpatrick. 2003. Growth kinetics and hydrolytic enzyme production of Pseudomonas spp. isolated from pasteurized milk. J. Dairy Res. 70:293-296. https://doi.org/10.1017/S0022029903006204.

Sunga, F. C. A., D. R. Heldman, and T. I. Hedrick. 1970. Microorganisms from arms and hands of dairy plant workers. J. Milk Food Technol. 33:178-181. https://doi.org/10.4315/0022-2747-33.5.178.

Ternström, A., A.-M. Lindberg, and G. Molin. 1993. Classification of the spoilage flora of raw and pasteurized bovine milk, with special reference to Pseudomonas and Bacillus. J. Appl. Bacteriol. 75:2534. https://doi.org/10.1111/j.1365-2672.1993.tb03403.x.

Tsarouhas, P. 2007. Implementation of total productive maintenance in food industry: A case study. J. Qual. Mainten. Eng. 13:5-18. https://doi.org/10.1108/13552510710735087.

Vangay, P., E. B. Fugett, Q. Sun, and M. Wiedmann. 2013. Food microbe tracker: A web-based tool for storage and comparison of food-associated microbes. J. Food Prot. 76:283-294.

Vinutha, H. P., B. Poornima, and B. M. Sagar. 2018. Detection of outliers using interquartile range technique from intrusion dataset. Pages 511-518 in Information and Decision Sciences. S. Satapathy, J. Tavares, V. Bhateja, and J. Mohanty, ed. Springer Singapore.

Walker, S. J., P. Archer, and J. G. Banks. 1990. Growth of Listeria monocytogenes at refrigeration temperatures. J. Appl. Bacteriol. 68:157-162. https://doi.org/10.1111/j.1365-2672.1990.tb02561.x.

Werner, B. G., J. Y. Wu, and J. M. Goddard. 2019. Antimicrobial and antifouling polymeric coating mitigates persistence of Pseudomo- nas aeruginosa biofilm. Biofouling 35:785-795. https://doi.org/10 $1080 / 08927014.2019 .1660774$

$\mathrm{Xu}, \mathrm{P} .2021$. Dynamics of microbial competition, commensalism, and cooperation and its implications for coculture and microbiome engineering. Biotechnol. Bioeng. 118:199-209. https://doi.org/10 $.1002 /$ bit. 27562 .

Yousefi, H., H.-M. Su, S. M. Imani, K. Alkhaldi, C. D. M. Filipe, and T. F. Didar. 2019. Intelligent food packaging: A review of smart sensing technologies for monitoring food quality. ACS Sens. 4:808-821. https://doi.org/10.1021/acssensors.9b00440.

Zugarramurdi, A., M. A. Parin. L. Gadaleta, and H. M. Lupin. 2007. A quality cost model for food processing plants. J. Food Eng. 83:414-421. https://doi.org/10.1016/j.jfoodeng.2007.03.029.

Zwietering, M. H., J. T. de Koos, B. E. Hasenack, J. C. de Witt, and K. van't Riet. 1991. Modeling of bacterial growth as a function of temperature. Appl. Environ. Microbiol. 57:1094-1101. https://doi .org/10.1128/aem.57.4.1094-1101.1991.

\section{ORCIDS}

S. Lau () https://orcid.org/0000-0001-9052-5094

A. Trmcic $\odot$ https://orcid.org/0000-0002-2249-5839

N. H. Martin $\odot$ https://orcid.org/0000-0003-1704-0634

M. Wiedmann @ https://orcid.org/0000-0002-4168-5662

S. I. Murphy @ https://orcid.org/0000-0001-9092-0625 